NBER WORKING PAPER SERIES

\title{
CONSUMPTION AND THE STOCK \\ MARKET: INTERPRETING \\ INTERNATIONAL EXPERIENCE
}

John Y. Campbell

Working Paper 5610

\author{
NATIONAL BUREAU OF ECONOMIC RESEARCH \\ 1050 Massachusetts Avenue \\ Cambridge, MA 02138 \\ June 1996
}

This paper was prepared for the Economic Council of Sweden's conference on Financial Markets and the Macroeconomy, Stockholm, October 6, 1995. I am grateful to Lars-Erik Öller, Lars Svensson, and Anders Vredin for helpful comments, to Luis Viceira for exceptionally able research assistance, and to Barclays de Zoete Wedd Securities Limited, Morgan Stanley Capital International, David Barr and Paul Söderlind for providing data. This paper is part of NBER's research programs in Asset Pricing, Economic Fluctuations and Growth, and Monetary Economics. Any opinions expressed are those of the author and not those of the National Bureau of Economic Research.

(C) 1996 by John Y. Campbell. All rights reserved. Short sections of text, not to exceed two paragraphs, may be quoted without explicit permission provided that full credit, including (C) notice, is given to the source. 
NBER Working Paper 5610

June 1996

\title{
CONSUMPTION AND THE STOCK \\ MARKET: INTERPRETING \\ INTERNATIONAL EXPERIENCE
}

\begin{abstract}
This paper reviews the behavior of stock prices in relation to consumption. The paper lists some important stylized facts that characterize US data, and relates them to recent developments in equilibrium asset pricing theory. Data from other countries are examined to see which features of the US experience apply more generally. The paper argues that to make sense of stock market behavior one needs a model in which investors' risk aversion is both high and varying, such as the external habit-formation model of Campbell and Cochrane (1995).
\end{abstract}

John Y. Campbell

Department of Economics

Littauer Center

Harvard University

Cambridge, MA 02138

and NBER 
The behavior of aggregate stock prices is a subject of enduring fascination to investors, policymakers, and economists. In recent years stock markets have continued to show some familiar patterns, including high average returns and volatile and procyclical price movements. Economists have struggled to understand these patterns. If stock prices are determined by fundamentals, then what exactly are these fundamentals and what is the mechanism by which they move prices?

Researchers, working primarily with US data, have documented a host of interesting stylized facts about the stock market and its relation to short-term interest rates and aggregate consumption.

1. The average real return on stock is high. In quarterly US data over the period 1947.2 to 1993.4 , for example, the average real stock return has been $7.2 \%$ at an annual rate. (Here and throughout the paper, the word return is used to mean a log or continuously compounded return.)

2. The average riskless real interest rate is low. 3-month Treasury bills deliver a return that is riskless in nominal terms and close to riskless in real terms because there is only modest uncertainty about inflation at a 3-month horizon. In the postwar quarterly US data, the average real return on 3 -month Treasury bills has been $0.7 \%$ per year.

3. Real stock returns are volatile, with an annualized standard deviation of $15.8 \%$ in the US data.

4. The real interest rate is much less volatile. The annualized standard deviation of the real return on US Treasury bills is $1.8 \%$, and most of this is due to short-run inflation risk. The volatility of a measure of the ex ante real interest rate is likely to be lower than $1.8 \%$.

5. Real consumption growth is very smooth. The annualized standard deviation of the growth rate of seasonally adjusted real consumption of nondurables and services is $1.1 \%$ in the US data. 
6. Real dividend growth is extremely volatile at short horizons because dividend data are not adjusted to remove seasonality in dividend payments. The annualized quarterly standard deviation of real dividend growth is $29.0 \%$ in the US data. At longer horizons, however, the volatility of dividend grow th is intermediate between the volatility of stock returns and the volatility of consumption growth. At an annual frequency, for example, the volatility of real dividend growth is $7.3 \%$ in the US data.

7. Quarterly real consumption growth and real dividend growth have a very weak correlation of 0.05 in the US data, but the correlation increases at lower frequencies to slightly exceed 0.20 at horizons from 2 to 4 years.

8. Real consumption growth and real stock returns have a quarterly correlation of 0.21 in the US data. The correlation increases to 0.34 at a 1 -year horizon, and declines at longer horizons.

9. Quarterly real dividend growth and real stock returns have a very weak correlation of 0.04 in the US data, but the correlation increases steadily with the horizon. It is 0.14 at a 1-year horizon, 0.28 at a 2-year horizon, and 0.53 at a 4 -year horizon.

10. Real US consumption growth is not well forecast by its own history or by the stock market. The first-order autocorrelation of the quarterly growth rate of real nondurables and services consumption is a modest 0.2 , and the $\log$ price-dividend ratio forecasts less than $10 \%$ of the variation of real consumption growth at horizons of 1 to 4 years.

11. Real US dividend growth has some short-run forecastability arising from the seasonality of dividend payments. But it is not well forecast by the stock market. The log pricedividend ratio forecasts no more than about $9 \%$ of the variation of real dividend growth at horizons of 1 to 4 years.

12. The real interest rate has some positive serial correlation; its first-order autocorrelation in postwar quarterly US data is 0.5 . However the real interest rate is not well forecast 
by the stock market, since the log price-dividend ratio forecasts no more than $1 \%$ of the variation of the real interest rate at horizons of 1 to 4 years.

13. Excess returns on US stock over Treasury bills are highly forecastable. The log pricedividend ratio forecasts $20 \%$ of the variance of the excess return at a 1-year horizon, almost $40 \%$ at a 2 -year horizon, and $55 \%$ at a 4 -year horizon.

These facts raise two important questions for students of macroeconomics and finance.

- Why is the average stock return so high in relation to the average return on short debt?

\section{- Why are stock returns so volatile?}

Mehra and Prescott (1985) call the first question the "equity premium puzzle". ${ }^{2}$ Finance theory explains the expected excess return on any risky asset over the riskless interest rate as the quantity of risk times the price of risk. In a standard consumption-based asset pricing model of the type studied by Hansen and Singleton (1983), the quantity of stock market risk is measured by the covariance of the excess stock return with consumption growth, while the price of risk is the coefficient of relative risk aversion of a representative investor. The high average stock return and low riskless interest rate (stylized facts 1 and 2) imply that the expected excess return on stock, the equity premium, is high. But the smoothness of consumption (stylized fact 5) makes the covariance of stock returns with consumption low; hence the equity premium can only be explained by a very high coefficient of risk aversion.

Some authors, such as Kandel and Stambaugh (1991), have argued that risk aversion is indeed much higher than traditionally thought. However this can lead to the "riskfree rate puzzle" of Weil (1989). If investors are very risk averse, then they have a strong desire to transfer wealth from periods with high consumption to periods with low consumption. Since consumption has tended to grow steadily over time, high risk aversion makes investors want

\footnotetext{
2 For excellent recent surveys, see Cochrane and Hansen (1992) or Kocherlakota (1996). Cochrane and Hansen discuss the puzzle using the methodology of Hansen and Jagannathan (1992).
} 
to borrow to reduce the discrepancy between future consumption and present consumption. To reconcile this with the low real interest rate we observe, we must postulate that investors are extremely patient; their preferences give future consumption almost as much weight as current consumption, or even greater weight than current consumption. In other words they have a low or even negative rate of time preference.

I will call the second question the "stock market volatility puzzle". To understand the puzzle, it is helpful to classify the possible sources of stock market volatility. Recall first that prices, dividends, and returns are not independent but are linked by an accounting identity. If an asset's price is high today, then either its dividend must be high tomorrow, or its return must be low between today and tomorrow, or its price must be even higher tomorrow. If one excludes the possibility that an asset price can grow explosively forever in a "rational bubble", then it follows that an asset with a high price today must have some combination of high dividends over the indefinite future and low returns over the indefinite future. Investors must recognize this fact in forming their expectations, so when an asset price is high investors expect some combination of high future dividends and low future returns. Movements in prices must then be associated with some combination of changing expectations ("news") about future dividends and changing expectations about future returns; the latter can in turn be broken into news about future riskless real interest rates and news about future excess returns on stocks over short-term debt.

Until the early 1980's, most financial economists believed that there was very little predictable variation in stock returns and that dividend news was by far the most important factor driving stock market fluctuations. LeRoy and Porter (1981) and Shiller (1981) challenged this orthodoxy by pointing out that plausible measures of expected future dividends are far less volatile than real stock prices. Their work is related to stylized facts 6,9 , and 11.

Later in the 1980's Campbell and Shiller (1988a,b), Fama and French (1988a,b, 1989), Poterba and Summers (1988) and others showed that real stock returns are highly forecastable at long horizons. Even more striking, excess returns on stock over Treasury bills 
are just as forecastable as real returns on stock. This work is related to stylized facts 12 and 13. Campbell (1991) and Campbell and Ammer (1993) use this evidence to show that the great bulk of stock market volatility is associated with changing forecasts of excess stock returns. Changing forecasts of dividend growth and real interest rates are much less important empirically.

The stock market volatility puzzle is closely related to the equity premium puzzle. A complete model of stock market behavior must explain both the average level of stock prices and their movements over time. One strand of work on the equity premium puzzle makes this explicit by studying not the consumption covariance of measured stock returns, but the consumption covariance of returns on hypothetical assets whose dividends equal consumption. The same model is used to generate both the volatility of stock prices and the implied equity premium. This was the approach of Mehra and Prescott (1985), and many subsequent authors have followed their lead.

Unfortunately, it is not easy to construct a model that fits all the stylized facts given above. Even if one follows the literature in equating consumption and dividends, it is hard to produce sufficient variation in stock prices without excessive variation in expected consumption (dividend) growth and in riskless real interest rates. The standard model of Hansen and Singleton (1983) and Mehra and Prescott (1985), with a constant variance for consumption (dividend) growth, gets variation in stock prices relative to consumption (dividends) only from predictable variation in consumption (dividend) growth which creates predictable variation in the riskless real interest rate. In this model there is no predictable variation in excess stock returns.

Since the data suggest that predictable variation in excess returns is an important source of stock market volatility, researchers have begun to develop models in which the quantity of stock market risk or the price of risk change through time. ARCH models and other econometric methods show that the conditional variance of stock returns is highly variable. If this conditional variance is an adequate proxy for the quantity of stock market risk, then perhaps it can explain the predictability of excess stock returns. There are several problems with 
this approach. First, changes in conditional variance are most dramatic in daily or monthly data and are much weaker at lower frequencies. There is some business-cycle variation in volatility, but it does not seem strong enough to explain large movements in aggregate stock prices (Bollerslev, Chou, and Kroner 1992, Schwert 1989). Second, forecasts of excess stock returns do not move proportionally with estimates of conditional variance (Harvey 1989, 1991, Chou, Engle, and Kane 1992). Finally, one would like to derive stock market volatility endogenously within a model rather than treating it as an exogenous variable. There is little evidence of cyclical variation in consumption or dividend volatility that could explain the variation in stock market volatility.

A more promising possibility is that the price of risk varies over time. Campbell and Cochrane (1995), building on the work of Abel (1990), Constantinides (1990), and others, have recently proposed a simple asset pricing model with this property. Campbell and Cochrane suggest that assets are priced as if there were a representative agent who consumes aggregate consumption; but in a departure from the standard model, the agent's utility is a power function of the difference between consumption and "habit", where habit is a slowmoving nonlinear average of past aggregate consumption. This utility function makes the agent more risk-averse in bad times, when consumption is low relative to its past history, than in good times, when consumption is high relative to its past history. Stock market volatility is explained by a small amount of underlying consumption (dividend) risk, amplified by variable risk aversion; the equity premium is explained by high stock market volatility, together with a high average level of risk aversion.

This paper has two objectives. First, it tries to summarize recent work on stock price behavior, much of which is highly technical, in a way that is accessible to a broader professional audience. Second, the paper summarizes the behavior of stock markets in other countries and asks which of the US stylized facts hold true more generally. The recent theoretical literature is used to guide the exploration of the international data.

The organization of the paper is as follows. Section 1 introduces the international data and reviews stylized facts 1-9 to see which of them apply outside the United States. (Addi- 
tional details are given in a Data Appendix available from the author.) Section 2 discusses the equity premium puzzle, taking the volatility of stock returns as given. Section 3 discusses the stock market volatility puzzle. This section also reviews stylized facts $10-13$ in the international data. Section 4 presents the Campbell and Cochrane (1995) model of changing risk aversion and explores its relevance for the international data. Section 5 concludes. 


\section{International Stock Market Data}

The stylized facts described in the previous section apply to postwar quarterly US data. Most empirical work on stock prices uses this data set, or a longer annual US time series originally put together by Shiller (1981). But data on stock prices, interest rates, and consumption are also available for many other countries.

To construct an international quarterly data set, I use Morgan Stanley Capital International (MSCI) stock market data covering the period since 1970. I combine the MSCI data with macroeconomic data on consumption, interest rates, and the price level from the International Financial Statistics (IFS) of the International Monetary Fund. For some countries the IFS data are only available quarterly over a shorter sample period, so I use the longest available sample for each country. Sample start dates range from 1970.1 to 1978.4, and sample end dates range from 1993.3 to 1994.3. I work with data from 12 countries: Australia, Canada, France, Germany, Italy, Japan, the Netherlands, Spain, Sweden, Switzerland, the United Kingdom, and the United States.

For some purposes it is useful to have data over a much longer span of calendar time. I have been able to obtain annual data for Sweden and the UK over the period 1919-1993 to complement the US annual data for the period 1890-1992. The Swedish data come from Frennberg and Hansson (1992) and Hassler, Lundvik, Persson, and Söderlind (1994), while the UK data come from Barclays de Zoete Wedd Securities (1995) and Economist (1987). ${ }^{3}$

In working with international stock market data, it is important to keep in mind that different national stock markets are of very different sizes, both absolutely and in proportion to national GDP's. Table 1 illustrates this by reporting several measures of stock market capitalization for the quarterly MSCI data. Column 1 gives the market capitalization for each country's MSCI index at the end of 1993, in billions of \$US. Column 2 gives the market capitalization for each country as a fraction of its GDP. Column 3 gives the market capitalization for each country as a fraction of the US MSCI index capitalization. Column

\footnotetext{
${ }^{3}$ I acknowledge the invaluable assistance of Paul Söderlind with the Swedish data and David Barr with the UK data. Full details about the construction of the quarterly and annual data are given in a Data Appendix available from the author.
} 
4 gives the market capitalization for each country as a fraction of the value-weighted world MSCI index capitalization. Since the MSCI index for the United States is only a subset of the US market, the last row of the table gives the same statistics for the value-weighted index of New York Stock Exchange and American Stock Exchange stocks reported by the Center for Research in Security Prices (CRSP) at the University of Chicago.

Table 1 shows that most countries' stock markets are dwarfed by the US market. Column 3 , for example, shows that the Japanese MSCI index is worth only $65 \%$ of the US MSCI index, the UK MSCI index is worth only $30 \%$ of the US index, the French and German MSCI indexes are worth only $11 \%$ of the US index, and all other countries' indexes are worth less than $10 \%$ of the US index. Column 4 shows that the US and Japan together account for $66 \%$ of the world market capitalization, while the US, Japan, the UK, France, and Germany together account for $86 \%$. In interpreting these numbers one must keep in mind that the MSCI indexes do not cover the whole market in each country (the US MSCI index, for example, is worth about half the US CRSP index), but they do give a guide to relative magnitudes across countries.

Table 1 also shows that different countries' stock market values are very different as a fraction of GDP. If one thinks that total wealth-output ratios are likely to be fairly constant across countries, then this indicates that national stock markets are very different fractions of total wealth in different countries. In highly capitalized countries such as the UK and Switzerland, the MSCI index accounts for about $80 \%$ of GDP, whereas in Germany, Italy, and Spain, it accounts for less than $20 \%$ of GDP. The theoretical convention of treating the stock market as a claim to total consumption, or as a proxy for the aggregate wealth of an economy, makes much more sense in the highly capitalized countries. More generally, international differences in capitalization deserve further study.

Table 2 reports summary statistics for international returns. For each country the table reports the mean, standard deviation, and first-order autocorrelation of the real stock return and the real return on a short-term debt instrument. ${ }^{4}$ Both means and standard devia-

\footnotetext{
${ }^{4}$ As explained in the Data Appendix, the best available short-term interest rate is sometimes a Treasury bill rate and sometimes another money market interest rate.
} 
tions are given in annualized percentage points. To annualize the raw quarterly numbers, means are multiplied by 400 while standard deviations are multiplied by 200 (since standard deviations increase with the square root of the time interval in serially uncorrelated data).

The top panel of Table 2 gives numbers for the 12-country quarterly MSCI data; the middle panel gives numbers for the standard postwar quarterly US data set summarized in the introduction; and the bottom panel gives numbers for the long-term annual data sets. The table shows that the first four stylized facts given in the introduction are fairly robust across countries.

1. Stock markets have delivered average real returns of $5 \%$ or better in almost every country and time period. The exceptions to this occur in short-term quarterly data, and are concentrated in markets that are particularly small relative to GDP (Italy and Spain), or that predominantly represent claims on natural resources (Australia and Canada).

2. Short-term debt has rarely delivered an average real return above $3 \%$. The exceptions to this occur in two countries, Germany and the Netherlands, whose sample periods begin in the late 1970's and thus exclude the surprise inflation of the oil-shock period.

3. The annualized standard deviation of stock returns ranges from $16 \%$ to $28 \%$. It is striking that the two markets with the highest volatility, Italy and Spain, are the two smallest markets relative to GDP and the two markets with anomalously low average returns.

4. In quarterly data the annualized volatility of real returns on short debt is $4 \%$ for Spain, $3 \%$ for Italy, Sweden, and the UK, and well below $3 \%$ for all other countries. Volatility is higher in long-term annual data because of large swings in inflation in the interwar period, particularly in 1919-21. Much of the volatility in these real returns is probably due to unanticipated inflation and does not reflect volatility in the ex ante real interest rate.

Table 3 turns to data on aggregate consumption and stock market dividends. The table is organized in the same way as Table 2. It illustrates the robustness of two more of the stylized facts given in the introduction.

5. In the postwar period the annualized standard deviation of real consumption growth is never above $3 \%$. This is true even though data are used on total consumption, rather 
than nondurables and services consumption, for all countries other than the US. Even in the longer annual data, which include the turbulent interwar period, consumption volatility is only slightly higher than $3 \%$.

6. The volatility of dividend growth is much greater than the volatility of consumption growth, but generally less than the volatility of stock returns. The exceptions to this occur in countries with highly seasonal dividend payments; these countries have large negative autocorrelations for quarterly dividend growth and much smaller volatility when dividend growth is measured over a full year rather than over a quarter.

Table 4 reports the contemporaneous correlations among real consumption growth, real dividend growth, and stock returns. It turns out that these correlations are somewhat sensitive to the timing convention used for consumption. A timing convention is needed because the level of consumption is a flow during a quarter rather than a point-in-time observation. If we think of a given quarter's consumption data as measuring consumption at the beginning of the quarter, then consumption growth for the quarter is next quarter's consumption divided by this quarter's consumption. If on the other hand we think of the consumption data as measuring consumption at the end of the quarter, then consumption growth is this quarter's consumption divided by last quarter's consumption. Table 4 uses the former, "beginningof-quarter" timing convention because this produces a higher contemporaneous correlation between consumption growth and stock returns.

The timing convention has less effect on correlations when the data are measured at longer horizons. Table 4 also shows how the correlations among real consumption growth, real dividend growth, and real stock returns vary with the horizon. Each pairwise correlation among these series is calculated for horizons of $1,4,8$, and 16 quarters in the quarterly data and for horizons of $1,2,4$, and 8 years in the long-term annual data. The table illustrates three more stylized facts from the introduction.

7. Real consumption growth and dividend growth are generally weakly positively correlated in the quarterly data. In many, but not all, countries the correlation increases strongly with the measurement horizon. The quarterly correlation is negative for the Netherlands but 
turns positive at longer horizons. Negative long-horizon correlations appear for Italy (with a very small stock market), Japan (with anomalous dividend behavior), and Switzerland. The correlations of consumption and dividend growth are moderately positive in the longer-term annual data sets.

8. The correlations between real consumption growth rates and stock returns are quite variable across countries. In many countries the quarterly correlations are small but increase somewhat at horizons of 1 or 2 years. The correlations are moderately positive in the longerterm annual data sets.

9. The correlations between real dividend growth rates and stock returns are small at a quarterly horizon but increase dramatically with the horizon. This pattern holds in every country. The correlations also increase strongly with the horizon in the longer-term annual data.

After this preliminary look at the data, I now use some simple finance theory to interpret the stylized facts. 


\section{The Equity Premium Puzzle}

To understand the equity premium puzzle, consider the intertemporal choice problem of a representative investor who can trade freely in some asset $i$ and can obtain a gross rate of return $\left(1+R_{i, t+1}\right)$ on the asset held from time $t$ to time $t+1$. If the investor consumes $C_{t}$ at time $t$ and has time-separable utility with discount factor $\delta$ and period utility $U\left(C_{t}\right)$, then her first-order condition is

$$
U^{\prime}\left(C_{t}\right)=\delta \mathrm{E}_{t}\left[\left(1+R_{i, t+1}\right) U^{\prime}\left(C_{t+1}\right)\right]
$$

The left hand side of (1) is the marginal utility cost of consuming one real dollar less at time $t$; the right hand side is the expected marginal utility benefit from investing the dollar in asset $i$ at time $t$, selling it at time $t+1$, and consuming the proceeds. The investor equates marginal cost and marginal benefit, so (1) must describe the optimum.

The classic statement of the equity premium puzzle assumes that there is a representative agent who maximizes a time-separable power utility function:

$$
\operatorname{Max} \sum_{j=0}^{\infty} \delta^{j} \frac{C_{t+j}^{1-\gamma}}{1-\gamma},
$$

where $\gamma$ is the coefficient of relative risk aversion. This utility function has several important properties. First, it is scale-invariant; with constant return distributions, risk premia do not change over time as aggregate wealth and the scale of the economy increase. Related to this, if different investors in the economy have different wealth levels but the same power utility function, then they can be aggregated into a single representative investor with the same utility function as the individual investors. A possibly less desirable property of power utility is that the elasticity of intertemporal substitution is the reciprocal of the coefficient of relative risk aversion $\gamma$. Epstein and Zin (1991) and Weil (1989) have proposed a more general utility specification that preserves the scale-invariance of power utility but breaks the tight link between the coefficient of relative risk aversion and the elasticity of intertemporal substitution. 
Equation (2) implies that $U^{\prime}\left(C_{t}\right)=C_{t}^{-\gamma}$, so dividing (1) by $U^{\prime}\left(C_{t}\right)$ we get

$$
1=\mathrm{E}_{t}\left[\left(1+R_{\mathrm{i}, t+1}\right) \delta\left(\frac{C_{t+1}}{C_{t}}\right)^{-\gamma}\right] .
$$

This way of writing the model is due originally to Grossman and Shiller (1981); Hansen and Jagannathan (1992) have developed its implications in detail.

For simplicity I now follow Hansen and Singleton (1983) and assume that the joint conditional distribution of asset returns and consumption is lognormal and homoskedastic. While these assumptions are not literally realistic - stock returns in particular have fat-tailed distributions with variances that change over time - they do make it easier to discuss the main forces that should determine the equity premium.

When a random variable $X$ is conditionally lognormally distributed, it has the convenient property that

$$
\log \mathrm{E}_{t} X=\mathrm{E}_{t} \log X+\frac{1}{2} \operatorname{Var}_{t} \log X,
$$

where $\operatorname{Var}_{t} \log X \equiv \mathrm{E}_{t}\left[\left(\log X-\mathrm{E}_{t} \log X\right)^{2}\right]$. If in addition $X$ is conditionally homoskedastic, then $\operatorname{Var}_{t} \log X=\mathrm{E}\left[\left(\log X-\mathrm{E}_{t} \log X\right)^{2}\right]=\operatorname{Var}\left(\log X-\mathrm{E}_{t} \log X\right)$. Thus with joint conditional lognormality and homoskedasticity of asset returns and consumption, I can take logs of (3) and obtain

$$
0=\mathrm{E}_{t} r_{i, t+1}+\log \delta-\gamma \mathrm{E}_{t} \Delta c_{t+1}+\left(\frac{1}{2}\right)\left[\sigma_{i}^{2}+\gamma^{2} \sigma_{c}^{2}-2 \gamma \sigma_{i c}\right]
$$

Here $c_{t}=\log \left(C_{t}\right)$ and $r_{i t}=\log \left(1+R_{i t}\right)$, while $\sigma_{i}^{2}$ denotes the unconditional variance of $\log$ return innovations $\operatorname{Var}\left(r_{i, t+1}-\mathrm{E}_{t} r_{i, t+1}\right), \sigma_{c}^{2}$ denotes the unconditional variance of $\log$ consumption innovations $\operatorname{Var}\left(c_{t+1}-\mathrm{E}_{t} c_{t+1}\right)$, and $\sigma_{\mathrm{ic}}$ denotes the unconditional covariance of innovations $\operatorname{Cov}\left(r_{i, t+1}-\mathrm{E}_{t} r_{\mathrm{i}, t+1}, c_{t+1}-\mathrm{E}_{t} c_{t+1}\right)$.

Equation (5) has both time-series and cross-sectional implications. Consider first an asset with a riskless real return $r_{f, t+1}$. For this asset the return innovation variance $\sigma_{f}^{2}$ and the covariance $\sigma_{f c}$ are both zero, so the riskless real interest rate obeys

$$
r_{f, t+1}=-\log \delta+\gamma \mathrm{E}_{t} \Delta c_{t+1}-\frac{\gamma^{2} \sigma_{c}^{2}}{2}
$$

This equation says that the riskless real rate is linear in expected consumption growth, with slope coefficient equal to the coefficient of relative risk aversion. 
The assumption of homoskedasticity makes the log risk premium on any asset over the riskless real rate constant, so expected real returns on other assets are also linear in expected consumption growth with slope coefficient $\gamma$. The log risk premium is

$$
\mathrm{E}_{t}\left[r_{i, t+1}-r_{f, t+1}\right]+\frac{\sigma_{i}^{2}}{2}=\gamma \sigma_{i c} .
$$

The variance term on the left hand side of (7) is a Jensen's Inequality adjustment arising from the fact that we are describing expectations of log returns. This term would disappear if we rewrote the equation in terms of the log expectation of the ratio of gross returns: $\log \mathrm{E}_{t}\left[\left(1+R_{i, t+1}\right) /\left(1+R_{f, t+1}\right)\right]=\gamma \sigma_{i c}$. The right hand side of $(7)$ says that the $\log$ risk premium is determined by the coefficient of relative risk aversion times covariance with consumption growth. Intuitively, an asset with a high consumption covariance tends to have low returns when consumption is low and the marginal utility of consumption is high. Such an asset is risky in that it fails to deliver wealth precisely when wealth is most valuable to the investor. The investor therefore demands a large risk premium to hold it.

Table 5 uses equation (7) to illustrate the equity premium puzzle. For each data set the table reports the average excess log return on stock over short-term debt, adjusted for Jensen's Inequality by adding one-half the sample variance of the excess log return to get a sample estimate of the left hand side of (7). This adjusted average excess return is multiplied by 400 to express it in annualized percentage points. The table then reports the annualized standard deviation of the excess log stock return (given earlier in Table 2), the annualized standard deviation of consumption growth (given earlier in Table 3), the correlation between the excess log stock return and consumption growth, and the product of these three variables which is the annualized covariance $\sigma_{i c}$ between the log stock return and consumption growth. Finally, the table gives two columns with implied risk aversion coefficients. The column headed RRA(1) uses equation (7) directly, dividing the adjusted average excess return by the estimated covariance to get estimated risk aversion. ${ }^{5}$ The column headed RRA(2) sets the correlation of stock returns and consumption growth equal to one before calculating risk

\footnotetext{
${ }^{5}$ The calculation is done correctly, in natural units, even though the table reports average excess returns and covariances in percentage point units. Equivalently, the ratio of the quantities given in the table is multiplied by 100 .
} 
aversion. This is often done implicitly in calibration exercises such as Mehra and Prescott (1985), Campbell and Cochrane (1995), or Abel (1996).

Table 5 shows that the equity premium puzzle is a robust phenomenon in international data. The coefficients of relative risk aversion in the RRA(1) column are generally extremely large. They are usually many times greater than 10 , the maximum level considered plausible by Mehra and Prescott (1985). In a few cases the risk aversion coefficients are negative because the estimated covariance of stock returns with consumption growth is negative, but in these cases the covariance is extremely close to zero. Even when one ignores the low correlation between stock returns and consumption growth and gives the model its best chance by setting the correlation to one, the $\mathrm{RRA}(2)$ column still has risk aversion coefficients above 10 in most cases. Thus the fact shown in Table 4, that for some countries the correlation of stock returns and consumption increases with the horizon, is unable by itself to resolve the equity premium puzzle.

The risk aversion estimates in Table 5 are of course point estimates and are subject to sampling error. No standard errors are reported for these estimates. However authors such as Cecchetti, Lam, and Mark (1993) and Kocherlakota (1996), studying the long-run annual US data, have found small enough standard errors that they can reject risk aversion coefficients below about 8 at conventional significance levels.

One response to the equity premium puzzle is to consider larger values for the coefficient of relative risk aversion $\gamma$. Kandel and Stambaugh (1991) have advocated this. ${ }^{6}$ However this leads to a second puzzle. Equation (5) implies that the unconditional mean riskless interest rate is

$$
\mathrm{E} r_{f, t+1}=-\log \delta+\gamma g-\frac{\gamma^{2} \sigma_{c}^{2}}{2}
$$

where $g$ is the mean growth rate of consumption. Since $g$ is positive, as shown in Table 3 , high values of $\gamma$ imply high values of $\gamma g$. Ignoring the term $-\gamma^{2} \sigma_{c}^{2} / 2$ for the moment, this

\footnotetext{
${ }^{6}$ One might think that introspection would be sufficient to rule out very large values of $\gamma$, but Kandel and Stambaugh (1991) point out that introspection can deliver very different estimates of risk aversion depending on the size of the gamble considered. This suggests that introspection can be misleading or that some more general model of utility is needed.
} 
can be reconciled with low average short-term real interest rates, shown in Table 2, only if the discount factor $\delta$ is close to or even greater than one, corresponding to a low or even negative rate of time preference. This is the riskfree rate puzzle emphasized by Weil (1989).

Intuitively, the riskfree rate puzzle is that if investors are risk-averse then with power utility they must also be extremely unwilling to substitute intertemporally. Given positive average consumption growth, a low riskless interest rate and a positive rate of time preference, such investors would have a strong desire to borrow from the future to reduce their average consumption growth rate. A low riskless interest rate is possible in equilibrium only if investors have a negative rate of time preference that reduces their desire to borrow.

Of course, if the risk aversion coefficient $\gamma$ is high enough then the negative quadratic $\gamma^{2}$ term in equation (8) dominates the linear term and pushes the riskless interest rate down again. The quadratic term reflects precautionary savings; risk-averse agents with uncertain consumption streams have a precautionary desire to save, which can work against their desire to borrow. But a reasonable rate of time preference is obtained only as a knife-edge case.

Table 6 illustrates the riskfree rate puzzle in international data. The table first shows the average riskfree rate from Table 2 and the mean consumption growth rate and standard deviation of consumption growth from Table 3. These moments and the risk aversion coefficients calculated in Table 5 are substituted into equation (8), and the equation is solved for an implied time preference rate. The time preference rate is reported in percentage points per year; it can be interpreted as the riskless real interest rate that would prevail if consumption were known to be constant forever at its current level, with no growth and no volatility. The table shows that risk aversion coefficients in the RRA(2) range imply negative time preference rates, whereas larger risk aversion coefficients in the RRA(1) range imply time preference rates that are often positive but always implausible and vary wildly across countries.

The discussion in this section has taken the volatility of stock returns as given. I now ask what accounts for this volatility. 


\section{The Stock Market Volatility Puzzle}

To understand the stock market volatility puzzle, it is useful to have a framework relating movements in stock prices to movements in expected future dividends and discount rates. The present value model of stock prices is intractabiy nonlinear when expected stock returns are time-varying, but Campbell and Shiller (1988a) have suggested a useful loglinear approximation to the exact present value model. Campbell and Shiller's loglinear relation between prices, dividends, and returns provides an accounting framework: High prices must eventually be followed by high future dividends or low future returns, and high prices must be associated with high expected future dividends or low expected future returns. Similarly, high returns must be associated with upward revisions in expected future dividends or downward revisions in expected future returns.

The loglinear approximation starts with the definition of the $\log$ return on stock $i, r_{i, t+1} \equiv$ $\log \left(P_{i, t+1}+D_{i, t+1}\right)-\log \left(P_{i t}\right)$. The timing convention here is that prices are measured at the end of each period so that they represent claims to next period's dividends. The log return is a nonlinear function of $\log$ prices $p_{i t}$ and $p_{i, t+1}$ and and $\log$ dividends $d_{i, t+i}$, but it can be approximated around the mean $\log$ dividend-price ratio, $\left(\overline{d_{i t}-p_{i t}}\right)$, using a first-order Taylor expansion. The resulting approximation is

$$
r_{i, t+1} \approx k_{i}+\rho_{i} p_{i, t+1}+\left(1-\rho_{i}\right) d_{i, t+1}-p_{i t}
$$

where $\rho_{i}$ and $k_{i}$ are parameters of linearization defined by $\rho_{i} \equiv 1 /\left(1+\exp \left(\overline{d_{i t}-p_{i t}}\right)\right)$ and $k_{i} \equiv-\log \left(\rho_{i}\right)-\left(1-\rho_{i}\right) \log \left(1 / \rho_{i}-1\right)$. When the dividend-price ratio is constant, then $\rho_{i}=P_{i} /\left(P_{i}+D_{i}\right)$, the ratio of the ex-dividend to the cum-dividend stock price. In the postwar quarterly US data shown in Table 3, the average price-dividend ratio has been 26.4 on an annual basis, implying that $\rho_{i}$ should be about 0.964 in annual data. The Taylor approximation (9) replaces the $\log$ of the sum of the stock price and the dividend in the exact relation with a weighted average of the log stock price and the log dividend. The log stock price gets a weight $\rho_{i}$ close to one, while the $\log$ dividend gets a weight $1-\rho_{i}$ close to zero because the dividend is on average much smaller than the stock price, so a given 
percentage change in the dividend has a much smaller effect on the return than a given percentage change in the price.

Equation (9) is a linear difference equation for the log stock price. Solving forward, imposing the "no-bubble" condition that $\lim _{j \rightarrow \infty} \rho_{i}^{j} p_{t+j}=0$, taking expectations, and subtracting the current dividend, one gets

$$
p_{i t}-d_{i t}=\frac{k_{i}}{1-\rho_{i}}+\mathrm{E}_{t} \sum_{j=0}^{\infty} \rho_{i}^{j}\left[\Delta d_{i, t+1+j}-r_{i, t+1+j}\right] .
$$

This equation says that the $\log$ price-dividend ratio is high when dividends are expected to grow rapidly, or when stock returns are expected to be low. The equation should be thought of as an accounting identity rather than a behavioral model; it has been obtained merely by approximating an identity, solving forward subject to a terminal condition, and taking expectations. Intuitively, if the stock price is high today, then from the definition of the return and the assumption that the stock price is non-explosive, there must either be high dividends or low stock returns in the future. Investors must then expect some combination of high dividends and low stock returns if their expectations are to be consistent with the observed price.

Equation (10) describes the log price-dividend ratio rather than the log price itself. This is a useful way to write the model because in many data sets dividends appear to follow a $\log$ linear unit root process, so that $\log$ dividends and $\log$ prices are nonstationary. In this case changes in $\log$ dividends are stationary, so from (10) the $\log$ price-dividend ratio is stationary provided that the expected stock return is stationary. Thus log stock prices and dividends are cointegrated, and the stationary linear combination of these variables involves no unknown parameters since it is just the log ratio.

Table 7 reports some summary statistics for international stock prices in relation to dividends. The table gives the average price-dividend ratio, the standard deviation of the $\log$ price-dividend ratio in natural units, the first-order autocorrelation of the log price-dividend ratio, average growth rates of prices, dividends, and the log price-dividend ratio in percentage points per year, and a test statistic for the null hypothesis that the log price-dividend ratio 
has a unit root. Following standard practice, the price-dividend ratio is measured as the ratio of the current stock price to the total of dividends paid during the past year.

Average price-dividend ratios vary considerably across countries but generally lie between 20 and 30. The extreme outlier is Japan, which has an average price-dividend ratio of 86 . The volatility and first-order autocorrelation of the log price-dividend ratio are also unusually high for Japan, reflecting an upward trend in the Japanese log price-dividend ratio for much of the sample period which is also visible in the average growth rates of prices and dividends at the right of the table.

Other countries in the quarterly data set, with the exception of France, have first-order autocorrelation coefficients for the $\log$ price-dividend ratio of between 0.85 and 0.95 . Unit root tests do not reject the unit root null hypothesis for most of these countries, but this may reflect low power of the tests in short data samples. Equation (10) implies that the $\log$ price-dividend ratio must be stationary if real dividend growth and stock returns are stationary, so this gives some reason to assume stationarity for the series.

So far I have written asset prices as linear combinations of expected future dividends and returns. Following Campbell (1991), I can also write asset returns as linear combinations of revisions in expected future dividends and returns. Substituting (10) into (9), I obtain

$$
r_{i, t+1}-\mathrm{E}_{t} r_{i, t+1}=\left(\mathrm{E}_{t+1}-\mathrm{E}_{t}\right) \sum_{j=0}^{\infty} \rho_{i}^{j} \Delta d_{i, t+1+j}-\left(\mathrm{E}_{t+1}-\mathrm{E}_{t}\right) \sum_{j=1}^{\infty} \rho_{i}^{j} r_{i, t+1+j} .
$$

This equation says that unexpected stock returns must be associated with changes in expectations of future dividends or real returns. An increase in expected future dividends is associated with a capital gain today, while an increase in expected future returns is associated with a capital loss today. The reason is that with a given dividend stream, higher future returns can only be generated by future price appreciation from a lower current price.

I now use this accounting framework to illustrate the stock market volatility puzzle. Following Campbell (1986) and Abel (1996) I assume that the aggregate stock market, denoted by subscript $m$, pays a dividend equal to aggregate consumption raised to a power $\lambda$. In logs, we have

$$
d_{m t}=\lambda c_{t}
$$


Abel (1996) shows that the coefficient $\lambda$ can be interpreted as a measure of leverage. The standard model of Lucas (1978), Grossman and Shiller (1981), and Mehra and Prescott (1985) has $\lambda=1$, but dividends can be made more volatile than consumption by setting $\lambda>1$.

The representative agent asset pricing model with power utility, conditional lognormality, and homoskedasticity (equations (6) and (7)) implies that

$$
\mathrm{E}_{t} r_{m, t+1}=\mu_{m}+\gamma \mathrm{E}_{t} \Delta c_{t+1}
$$

The expected log return on the aggregate stock market, like the expected log return on any other asset, is just a constant term plus $\gamma$ times expected consumption growth.

Substituting equations (12) and (13) into equations (10) and (11), I find that

$$
p_{m t}-d_{m t}=\frac{k_{m}}{1-\rho_{m}}+(\lambda-\gamma) \mathrm{E}_{t} \sum_{j=0}^{\infty} \rho_{m}^{j} \Delta c_{t+1+j}
$$

and

$$
r_{m, t+1}-\mathrm{E}_{t} r_{m, t+1}=\lambda\left(\Delta c_{t+1}-\mathrm{E}_{t} \Delta c_{t+1}\right)+(\lambda-\gamma)\left(\mathrm{E}_{t+1}-\mathrm{E}_{t}\right) \sum_{j=1}^{\infty} \rho_{m}^{j} \Delta c_{t+1+j} .
$$

Expected future consumption growth has offsetting effects on the log price-dividend ratio. It has a direct positive effect by increasing expected future dividends $\lambda$-for-one, but it has an indirect negative effect by increasing expected future real interest rates $\gamma$-for-one. The unexpected $\log$ return on the stock market is $\lambda$ times contemporaneous unexpected consumption growth (since contemporaneous consumption growth increases the contemporaneous dividend $\lambda$-for-one), plus $(\lambda-\gamma)$ times the discounted sum of revisions in expected future consumption growth.

These equations can be simplified if I assume with Mehra and Prescott (1985) that aggregate consumption growth follows a first-order autoregressive $(\operatorname{AR}(1))$ process of the form

$$
\Delta c_{t+1}=(1-\phi) g+\phi \Delta c_{t}+\tilde{c}_{t+1}
$$

where $g$ is mean consumption growth and $\tilde{c}_{t+1}$ denotes the innovation in consumption. The coefficient $\phi$ is the first-order autocorrelation coefficient for consumption growth, as reported 
in Table 3. Equation (16) allows me to rewrite (14) and (15) as

$$
p_{m t}-d_{m t}=\frac{k_{m}+(\lambda-\gamma g)}{1-\rho_{m}}+\frac{(\lambda-\gamma) \phi}{1-\rho_{m} \phi}\left(\Delta c_{t}-g\right)
$$

and

$$
r_{m, t+1}-\mathrm{E}_{t} r_{m, t+1}=\left(\frac{\lambda-\gamma \rho_{m} \phi}{1-\rho_{m} \phi}\right) \tilde{c}_{t+1} .
$$

These formulas show how difficult it is to account for stock market volatility within the standard model. First consider the case where $\phi>0$, so consumption growth is positively autocorrelated. In this case a positive consumption shock raises the current dividend and expected future dividend growth, but it also raises real interest rates. These offsetting effects make it hard to explain both the equity premium and the volatility of stock prices. From the previous section we know that a large $\gamma$ is needed to explain the equity premium; but then $\lambda-\gamma \rho_{m} \phi$ tends to be small (implying that stock returns are not volatile) or even negative (implying that stock returns are negatively correlated with consumption and the equity premium is negative).

Next consider the case where $\phi<0$. Here a positive consumption shock raises the current dividend, lowers expected future dividend growth, and lowers real interest rates. Now $\lambda-\gamma \rho_{m} \phi$ can be large and positive when $\gamma$ is large, implying volatile and procyclical stock prices.

Unfortunately this case has several unappealing implications. The log price-dividend ratio is a linear function of consumption growth so it follows an $\operatorname{AR}(1)$ process with the same persistence parameter $\phi$ as consumption growth. In the data, log price-dividend ratios have large positive autocorrelations (Table 7) which are inconsistent with $\phi<0$.

Negative autocorrelations in consumption growth also tend to make the riskless real interest rate volatile relative to the $\log$ price-dividend ratio. The price-dividend ratio reflects a discounted sum of long-run expected future real interest rates, and this discounted sum is less volatile than the current real interest rate when consumption growth and hence the real interest rate are negatively autocorrelated. As $\gamma$ increases, the ratio $\operatorname{Var}\left(r_{f t}\right) / \operatorname{Var}\left(p_{m t}-d_{m t}\right)$ approaches $\left(1-\rho_{m} \phi\right)^{2}$, which is greater than one when $\phi<0$. Empirically, the standard 
deviations for real returns on short-term debt given in Table 2 (which are reported in percentage points) are much smaller than the standard deviations for log price-dividend ratios given in Table 7 (which are reported in natural units). ${ }^{7}$

Finally, it is troubling that the standard model must rely so heavily on negative autocorrelation of consumption growth, for which there is no strong evidence. While some countries in Table 4 show negative autocorrelation in consumption growth, this is by no means a consistent pattern. 8 out of 12 quarterly datasets show negative autocorrelation, but only 4 of these negative correlations are less than -0.1 , and 2 out of 3 annual data sets show positive autocorrelation. ${ }^{8}$

All of these calculations rely heavily on the assumptions of the representative agent model with power utility, lognormal distributions, and constant variances. Another way to use the loglinear asset pricing framework is to study the empirical relationships between $\log$ price-dividend ratios and future consumption or dividend growth rates, real interest rates, and excess stock returns. According to equation (10), the log price-dividend ratio embodies rational forecasts of dividend growth rates and stock returns (which in turn are the sum of real interest rates and excess stock returns), discounted to an infinite horizon. One can compare the empirical importance of these different forecasts by regressing long-horizon consumption and dividend growth rates, real interest rates, and excess stock returns onto the $\log$ price-dividend ratio.

Table 8 reports the results of this exercise. For each quarterly data set, consumption growth, dividend growth, the real interest rate, and the excess stock return are computed in natural units over 4,8 , and 16 quarters $(1,2$, and 4 years) and regressed onto the $\log$ pricedividend ratio divided by its standard deviation. Thus the regression coefficient gives the

\footnotetext{
${ }^{7}$ In most countries the level (not the $\mathrm{log}$ ) of the dividend-price ratio has a standard deviation close to that of the riskless real interest rate. Since the standard deviation of the dividend-price ratio is approximately the average level of the dividend-price ratio times the standard deviation of the log price-dividend ratio, this implies that the log price-dividend ratio has a standard deviation many times greater than the standard deviation of the riskless real interest rate.

${ }^{8}$ There are several data problems that may affect these autocorrelations, but they go in both directions. Consumption for most countries includes durables, which tends to bias autocorrelation downwards, and is time-averaged and seasonally adjusted, which tends to bias autocorrelation upwards.
} 
effect of a one standard deviation change in the log price-dividend ratio on the cumulative growth rate or rate of return in natural units. The table reports the regression coefficient, heteroskedasticity- and autocorrelation-consistent $t$ statistic, and $R^{2}$ statistic.

In the benchmark postwar quarterly US data, the log price-dividend ratio has no clear ability to forecast consumption growth, dividend growth, or the real interest rate at any horizon. What it does forecast is the excess return on stocks, with $t$ statistics that start above 4 and increase, and with $R^{2}$ statistics that start at 0.20 and increase to 0.55 at a 4-year horizon. In the introduction these results were summarized as stylized facts 10,11 , 12, and 13. Table 8 extends them to international data.

10. Regressions of consumption growth on the log price-dividend ratio give very mixed results across countries. There are statistically significant positive coefficients in Germany, the Netherlands, and Spain, but statistically significant negative coefficients in Australia, Italy, and Japan. Canada, France, Sweden, Switzerland, and the UK resemble the US in that they have no statistically significant consumption growth forecasts.

11. Results are somewhat more promising for real dividend growth in many countries. Positive and statistically significant coefficients are found in Canada, France, Germany, Italy, Japan, Spain, Sweden, and the UK. It seems clear that changing forecasts of real dividend growth have some role to play in explaining stock market movements.

12. The short-term real interest rate does not seem to be a promising candidate for the driving force behind stock market fluctuations. One would expect to find high price-dividend ratios forecasting low real interest rates, but the regression coefficients are significantly positive in France, Italy, Japan, the Netherlands, Sweden, Switzerland, and the UK. This presumably reflects the fact that stock markets in most countries were depressed in the 1970's, when real interest rates were low, and buoyant during the 1980's, when real interest rates were high.

13. Finally, the log price-dividend ratio is a powerful forecaster of excess stock returns in almost every country. The regression coefficients are uniformly negative, and statistically significant everywhere except Japan. 
In the long-term annual data for Sweden, the UK, and the US, I use horizons of 1 year, 4 years, and 8 years. In the US data the $\log$ price-dividend ratio fails to forecast real dividend growth, suggesting that authors such as Barsky and De Long (1993) overemphasize the role of dividend forecasts in interpreting long-run US experience. Consistent with the quarterly results, the log price-dividend ratio also fails to forecast consumption growth or the real interest rate but does forecast excess stock returns.

The UK data are similar, although here the 8-year regression coefficients for consumption growth and dividend growth are even statistically significant with the wrong (negative) sign. The 8-year regression coefficient for the real interest rate is also significantly negative, consistent with the idea that the UK stock market is related to the real interest rate. But much the strongest relation is between the log price-dividend ratio and future excess returns on the UK stock market. The Swedish data are quite different; here the log price-dividend ratio forecasts dividend growth positively but has no predictive power for consumption growth, the real interest rate, or the excess log stock return.

Overall, these results suggest that a new model of stock market volatility is needed. The standard model drives all stock market fluctuations from changing forecasts of consumption (dividend) growth and real interest rates; forecasts of excess stock returns are constant. The data for many countries suggest instead that forecasts of consumption growth and real interest rates are constant, while the stock market is driven by changing forecasts of excess stock returns. 


\section{Changing Risk Aversion and the Stock Market Puz- zles}

In previous sections I have documented a challenging array of stylized facts and have discussed the problems they pose for standard asset pricing theory. Briefly, the equity premium puzzle suggests that risk aversion must be high on average to explain high average excess stock returns, while the stock market volatility puzzle suggests that risk aversion must vary over time to explain predictable variation in excess returns and the associated volatility of stock prices. I now present the model of Campbell and Cochrane (1995), which has these features, and show how it resolves at least some of the difficulties with the standard theory.

The Campbell-Cochrane model assumes that a representative investor derives utility from the level of consumption relative to a time-varying subsistence or habit level. The importance of habit has been emphasized by many authors, including Constantinides (1990), Ferson and Constantinides (1991), Heaton (1995), Ryder and Heal (1973), and Sundaresan (1989). Following Abel (1990), Campbell and Cochrane assume that the habit is external in the sense that it is determined by the consumption of the community as a whole, and not by the consumption of any individual investor. This assumption, which Abel calls "catching up with the Joneses", greatly simplifies the analysis since the investor does not have to calculate the effect of today's consumption decision on future marginal utility of consumption.

Campbell and Cochrane assume that log consumption follows a random walk. This fits the observation that most countries do not have highly predictable consumption or dividend growth rates (Tables 3 and 8 ). The consumption growth process is

$$
\Delta c_{t+1}=g+\tilde{c}_{t+1}
$$

where $\tilde{c}_{t+1}$ is a normal homoskedastic innovation with variance $\sigma_{c}^{2}$. This is just the $\operatorname{AR}(1)$ model (16) of the previous section, with zero persistence in consumption growth.

The utility function of the representative agent takes the form

$$
\mathrm{E}_{t} \sum_{j=0}^{\infty} \delta^{j} \frac{\left(C_{t+j}-X_{t+j}\right)^{1-\gamma}-1}{1-\gamma}
$$


Here $X_{t}$ is the level of habit, $\delta$ is the subjective discount factor, and $\gamma$ is the utility curvature parameter. Utility depends on a power function of the difference between consumption and habit; it is only defined when consumption exceeds habit.

It is convenient to capture the relation between consumption and habit by the surplus consumption ratio $S_{t}$, defined by

$$
S_{t} \equiv \frac{C_{t}-X_{t}}{C_{t}}
$$

The surplus consumption ratio is the fraction of consumption that exceeds habit and is therefore available to generate utility in (20). If habit $X_{t}$ is held fixed as consumption $C_{t}$ varies, the local coefficient of relative risk aversion is

$$
\frac{-C u_{C C}}{u_{C}}=\frac{\gamma}{S_{t}}
$$

where $u_{C}$ and $u_{C C}$ are the first and second derivatives of utility with respect to consumption. Risk aversion rises as the the surplus consumption ratio $S_{t}$ declines, that is, as consumption approaches the habit level. Note that $\gamma$, the curvature parameter in utility, is no longer the coefficient of relative risk aversion in this model.

To complete the description of preferences, one must specify how the habit $X_{t}$ evolves over time in response to aggregate consumption. Campbell and Cochrane suggest an AR(1) model for the $\log$ surplus consumption ratio, $s_{t} \equiv \log \left(S_{t}\right)$ :

$$
s_{t+1}=(1-\varphi) \bar{s}+\varphi s_{t}+\lambda\left(s_{t}\right) \tilde{c}_{t+1}
$$

The parameter $\varphi$ governs the persistence of the $\log$ surplus consumption ratio, while the "sensitivity function" $\lambda\left(s_{t}\right)$ controls the sensitivity of $s_{t+1}$ and thus of $\log$ habit $x_{t+1}$ to innovations in consumption growth $\tilde{c}_{t+1}$.

Equation (23) specifies that today's habit is a complex nonlinear function of current and past consumption. A linear approximation may help to understand it. If I substitute the definition $s_{t} \equiv \log \left(1-\exp \left(x_{t}-c_{t}\right)\right)$ into (23) and linearize around the steady state, I find that (23) is approximately a traditional habit-formation model in which log habit responds 
slowly and linearly to log consumption,

$$
x_{t+1} \approx(1-\varphi) \alpha+\varphi x_{t}+(1-\varphi) c_{t}=\alpha+(1-\varphi) \sum_{j=0}^{\infty} \varphi^{j} c_{t-j}
$$

The linear model (24) has two serious problems. First, when consumption follows an exogenous process such as (19) there is nothing to stop consumption falling below habit, in which case utility is undefined. This problem does not arise when one specifies a process for $s_{t}$, since any real value for $s_{t}$ corresponds to positive $S_{t}$ and hence $C_{t}>X_{t}$. Second, the linear model typically implies a highly volatile riskless real interest rate. The process (23) with a non-constant sensitivity function $\lambda\left(s_{t}\right)$ allows one to control or even eliminate variation in the riskless interest rate.

To derive the real interest rate implied by this model, one first calculates the marginal utility of consumption as

$$
u^{\prime}\left(C_{t}\right)=\left(C_{t}-X_{t}\right)^{-\gamma}=S_{t}^{-\gamma} C_{t}^{-\gamma}
$$

The riskless real interest rate is then

$$
\left(1+R_{t}^{f}\right)=\left(\delta \mathrm{E}_{t} \frac{U^{\prime}\left(C_{t+1}\right)}{U^{\prime}\left(C_{t}\right)}\right)^{-1}=\left(\delta \mathrm{E}_{t}\left(\frac{S_{t+1}}{S_{t}}\right)^{-\gamma}\left(\frac{C_{t+1}}{C_{t}}\right)^{-\gamma}\right)^{-1} .
$$

Taking logs, and using equations (19) and (23), the log riskless real interest rate is

$$
r_{t}^{\prime}=-\log (\delta)+\gamma g-\gamma(1-\varphi)\left(s_{t}-\bar{s}\right)-\frac{\gamma^{2} \sigma_{u}^{2}}{2}\left[\lambda\left(s_{t}\right)+1\right]^{2}
$$

The first two terms on the right hand side of (27) are familiar from the power utility model (8), while the last two terms are new. The third term (linear in $\left(s_{t}-\bar{s}\right)$ ) reflects intertemporal substitution. If the surplus consumption ratio is low, the marginal utility of consumption is high. However, the surplus consumption ratio is expected to revert to its mean, so marginal utility is expected to fall in the future. Therefore, the consumer would like to borrow and this drives up the equilibrium risk free interest rate. Note that what determines intertemporal substitution is mean-reversion in marginal utility, not meanreversion in consumption itself. In this model consumption follows a random walk so there 
is no mean-reversion in consumption; but habit formation causes the consumer to adjust gradually to a new level of consumption, creating mean-reversion in marginal utility.

The fourth term (linear in $\left[\lambda\left(s_{t}\right)+1\right]^{2}$ ) reflects precautionary savings. As uncertainty increases, consumers become more willing to save and this drives down the equilibrium riskless interest rate. Note that what determines precautionary savings is uncertainty about marginal utility, not uncertainty about consumption itself. In this model the consumption process is homoskedastic so there is no time-variation in uncertainty about consumption; but habit formation makes a given level of consumption uncertainty more serious for marginal utility when consumption is low relative to habit.

Equation (27) can be made to match the observed stability of real interest rates in two ways. First, it is helpful if the habit persistence parameter $\varphi$ is close to one, since this limits the strength of the intertemporal substitution effect. Second, the precautionary savings effect offsets the intertemporal substitution effect if $\lambda\left(s_{t}\right)$ declines with $s_{t}$. In fact, Campbell and Cochrane parameterize the $\lambda\left(s_{t}\right)$ function so that these two effects exactly offset each other everywhere, implying a constant riskless interest rate. They choose the sensitivity function $\lambda\left(s_{t}\right)$ to satisfy three conditions: 1) The real risk free rate is constant. 2) Habit is predetermined at the steady state $s_{t}=\bar{s}$. 3) Habit is predetermined near the steady state, or, equivalently, positive shocks to consumption may increase habit but never reduce it.

To understand conditions 2) and 3), recall that the traditional notion of habit makes it a predetermined variable. On the other hand habit cannot be predetermined everywhere, or a sufficiently low realization of consumption growth would leave consumption below habit. To make habit "as predetermined as possible", Campbell and Cochrane assume that habit is predetermined at and near the steady state. This also eliminates the counterintuitive possibility that positive shocks to consumption cause declines in habit.

Using these three conditions, Campbell and Cochrane show that the steady-state surplus consumption ratio must be a function of the other parameters of the model, and that the sensitivity function $\lambda\left(s_{t}\right)$ must take a particular form. Campbell and Cochrane pick parameters for the model by calibrating it to fit postwar quarterly US data. They choose the mean 
consumption growth rate $g=\mathbf{0 . 4 4 \%}$ per quarter and the standard deviation of consumption growth $\sigma_{v}=0.56 \%$ per quarter to match the moments of the US consumption data.

Campbell and Cochrane follow Mehra and Prescott by assuming that the stock market pays a dividend equal to consumption. They use numerical methods to find the pricedividend ratio for the stock market as a function of the state variable $s_{t}$. They set the persistence of the state variable, $\varphi$, equal to 0.97 to match the persistence of the log pricedividend ratio. ${ }^{9}$ They choose $\gamma=2.37$ to match the ratio of unconditional mean to unconditional standard deviation of return in US stock returns. These parameter values imply that at the steady state, the surplus consumption ratio $\bar{S}=0.05$ so habit is about $95 \%$ of consumption. Finally, Campbell and Cochrane choose the discount factor $\delta=0.97$ to give a riskless real interest rate of $1 \%$ per year.

It is important to understand that with these parameter values the model uses high average risk aversion to fit the high unconditional equity premium. Steady-state risk aversion is $\gamma / \bar{S}=2.37 / 0.05=48$. In this respect the model resembles a power utility model with a very high risk aversion coefficient.

There are however two important differences between the Campbell-Cochrane model and the power utility model with high risk aversion. First, the Campbell-Cochrane model avoids the riskfree rate puzzle of Weil (1989). Evaluating equation (27) at the steady state surplus consumption ratio and using the restrictions on the sensitivity function $\lambda\left(s_{t}\right)$, the constant riskless interest rate in the Campbell-Cochrane model is

$$
r_{t}^{f}=-\log (\delta)+\gamma g-\left(\frac{\gamma}{\bar{S}}\right)^{2} \frac{\sigma^{2}}{2}
$$

In the power utility model the same large coefficient $\gamma$ would appear in the consumption growth term and the consumption volatility term (equation (8)); in the Campbell-Cochrane model the curvature parameter $\gamma$ appears in the consumption growth term, and this is much lower than the steady-state risk aversion coefficient $\gamma / \bar{S}$ which appears in the consumption volatility term. Thus in the Campbell-Cochrane model a much lower value of the discount

\footnotetext{
${ }^{9}$ Rather than matching quarterly persistence directly, Campbell and Cochrane use the fourth root of the estimated annual persistence of the log price-dividend ratio.
} 
factor $\delta$ is consistent with the average level of the risk free interest rate, and the model implies a less sensitive relationship between mean consumption growth and interest rates. ${ }^{10}$

Second, the Campbell-Cochrane model has risk aversion that varies with the level of consumption, whereas a power utility model has constant risk aversion. The time-variation in risk aversion generates predictable movements in excess stock returns like those documented in Table 8, enabling the Campbell-Cochrane model to solve the stock market volatility puzzle. Results are reported in detail in Campbell and Cochrane (1995).

A full application of the Campbell-Cochrane model to international data would be out of keeping with the exploratory spirit of this paper. Instead, I undertake a more modest exercise. I use the traditional linear habit-formation model (equation (24)) to construct the difference between log consumption and "habit", where habit is just a backward moving average of past log consumption. That is, I construct $c_{t}-x_{t}$ where $x_{t}=g+\varphi x_{t-1}+(1-\varphi) c_{t-1}$ and at the first date in the sample "habit" equals consumption. ${ }^{11}$ The parameter $\varphi$ is arbitrarily set to 0.97 in quarterly data, or $0.97^{4}$ in annual data. This can be seen as a simple way to construct a stochastically detrended, stationary consumption series.

According to the basic Campbell-Cochrane model, high levels of stochastically detrended consumption forecast low excess stock returns but do not forecast consumption growth or real interest rates. In this sense the stock market is "cyclical" but the real interest rate is not. Campbell and Cochrane also present a modification of the model that allows modest countercyclical variation in the real interest rate; the modified model implies that high levels of stochastically detrended consumption forecast low real interest rates.

Table 9 repeats the regressions of Table 8 using the stochastically detrended consumption series for each country as the explanatory variable in place of the log price-dividend ratio. Once again the dependent variables are measured in natural units and the explanatory

\footnotetext{
${ }^{10}$ The preferences suggested by Epstein and Zin (1991) and Weil (1989), which break the link between the coefficient of relative risk aversion and the elasticity of intertemporal substitution, also allow average consumption growth to have a much smaller effect than consumption volatility on the risk free interest rate, but these preferences do not display time-varying risk aversion.

${ }^{11}$ In the underlying theory, of course, habit must lie below consumption but this is achieved in the linear model by subtracting a constant from the "habit" variable. The constant does not affect the dynamics of "habit" so I set it to zero in the empirical work
} 
variable is normalized by dividing by its standard deviation.

In quarterly data, some countries show some evidence of long-run mean reversion in consumption growth; stochastically detrended consumption forecasts slow consumption growth at long horizons in Australia, Canada, Germany, Italy, the Netherlands, Spain, and the United Kingdom. The long-run annual US data also show this pattern.

There is fairly strong evidence that the stochastically detrended consumption series forecasts real interest rates in the manner predicted by the modified Campbell-Cochrane model. All countries except Germany and the UK show negative coefficients in quarterly real interest rate regressions; however this effect is entirely absent in the long-run annual data.

Finally, the stochastically detrended consumption series often forecasts low excess stock returns. In quarterly data negative significant coefficients are found in Australia, France, the Netherlands, Spain, the UK, and the USA, while all three annual data sets display this pattern.

While these results are encouraging for the Campbell-Cochrane model, one should interpret them with some caution. Plots of the data show that for many countries the stochastically detrended consumption series exhibits low-frequency movements associated with the growth slowdown of the mid-1970's. These movements are different in nature from the cyclical swings emphasized by the Campbell-Cochrane model, and may distort some of the results. A symptom of this problem is that the correlation between stochastically detrended consumption and the log price-dividend ratio, which should be positive, is negative in 7 out of 12 quarterly data sets.

As a more direct way to examine the data, I plot consumption and its backward moving average for the annual Swedish, UK, and US data sets in Figures 1a, 2a, and 3a. I plot the stochastically detrended consumption series and the log price-dividend ratio (both normalized to have zero sample mean and unit sample standard deviation) for the same data sets in Figures $1 b, 2 b$, and $3 b$.

These figures illustrate the sense in which national stock markets respond to mediumterm swings in national consumption. In each of the three countries there are some important 
common movements in detrended consumption and the log price-dividend ratio. These are the movements that can be fit by an asset pricing model based on aggregate consumption, such as the model of Campbell and Cochrane (1995). But there are also some movements of the two series that do not correspond. In Sweden, for example, detrended consumption was particularly high in the 1920's and much lower in the 1980's, reflecting shifts in the longrun growth rate of the economy and in the allocation of national income between private consumption and government spending. The log price-dividend ratio on the other hand has tended to rise over the past 75 years. The Campbell-Cochrane model does not account for these low-frequency characteristics of the data. 


\section{Conclusion}

In this paper I have presented a list of stylized facts about US stock market behavior. I have shown that many of these facts describe the behavior of other countries' stock markets as well. The facts present two puzzles for standard asset pricing theory. The better-known puzzle is the large size of the average equity premium, but this is easily resolved by assuming that investors are highly risk-averse. The deeper puzzle is the high volatility of stock prices, which seems to be associated with predictable time-variation in excess stock returns. I have argued that this can be explained by a model of time-varying risk aversion such as the one presented by Campbell and Cochrane (1995).

In arguing for this model of stock market behavior I have left several important topics unexplored. First, I have followed the literature and have assumed that dividends equal consumption or equivalently, that the aggregate stock market equals total national wealth. This assumption is clearly untrue even for the United States, and is even less appropriate for countries with smaller stock markets. It is straightforward to generalize the assumption slightly by modelling stocks as a leveraged claim to aggregate consumption in the manner of Abel (1996), but it may be appropriate to go further by introducing human capital into the model in the manner of Campbell (1996) or by distinguishing between the consumption of stockholders and non-stockholders in the manner of Mankiw and Zeldes (1991).

Second, I have treated each national stock market as a separate entity with its own pricing model. That is, I have assumed that national economies are entirely closed so that there is no integrated world capital market. This assumption may be appropriate for examining long-term historical data, but it seems questionable under modern conditions. An interesting exercise would be to study the pricing of imperfectly correlated national stock markets in a model with an integrated world capital market. Such a model might be able to explain the fact that the short-run cross-country correlations of stock returns are higher than the short-run cross-country correlations of consumption or dividend growth rates. If there is a representative investor whose risk aversion varies over time, then shifting risk aversion would move all countries' stock markets together even if their dividends are only weakly correlated. 
Third, I have worked with a representative agent utility function and have not asked what features of individual preferences produce this utility function. Several authors have recently argued that rigidities in market structure with heterogeneous agents can produce shifting aggregate risk aversion (Aiyagari and Gertler 1995, Grossman and Zhou 1994). This deserves further exploration.

I conclude with some more general lessons for economic policymakers and commentators. The stock market is commonly used as a leading indicator of the state of the economy. The results of this paper suggest that while the stock market does forecast medium-term growth rates of corporate dividends, it is much less successful at forecasting medium-term growth rates of aggregate consumption. ${ }^{12}$

There has recently been a tendency for economists to downplay the importance of economic fluctuations in favor of an emphasis on long-term economic growth. But the model of habit formation presented here implies that consumers take fluctuations extremely seriously. Fluctuations have important negative effects on welfare because they move consumption in the short term, when agents have little time to adjust; reductions in long-term growth, on the other hand, allow agents' habit levels to adjust gradually.

This conclusion is not an artifact of a particular utility function and habit formation process. As Atkeson and Phelan (1994) emphasize, it must result from any utility function that explains the level of the equity premium. The choice between risky stocks and stable money market instruments offers investors a tradeoff between the mean growth rate of their wealth and the volatility of this growth rate. The fact that so much extra mean growth is available from volatile stock market investments implies that investors find volatility to be a serious threat to their welfare. Economic policymakers should take this into account when they face policy tradeoffs between economic growth and macroeconomic stability.

\footnotetext{
${ }^{12}$ This paper has not considered the ability of the stock market to forecast national income growth. See Cochrane (1994) and Campbell (1996) on the relations between aggregate consumption, income, and stock prices in US data.
} 


\section{References}

Abel, A.B. (1990), Asset Prices under Habit Formation and Catching Up with the Joneses, American Economic Review Papers and Proceedings 80, 38-42.

Abel, A.B. (1996), Risk Premia and Term Premia in General Equilibrium, unpublished paper, Wharton School, University of Pennsylvania.

Aiyagari, R. and M. Gertler (1995), Overreaction of Asset Prices in General Equilibrium, unpublished paper, Federal Reserve Bank of Minneapolis and New York University.

Atkeson, A. and C. Phelan (1994), Reconsidering the Costs of Business Cycles with Incomplete Markets, in S. Fischer and J.J. Rotemberg, eds., NBER Macroeconomics Annual 1994 (The MIT Press, Cambridge), 187-207.

Barclays de Zoete Wedd Securities Limited (1995), The BZW Equity-Gilt Study: Investment in the London Stock Market since 1918, London.

Barsky, R.B. and J.B. De Long (1993), Why Does the Stock Market Fluctuate?, Quarterly Journal of Economics 107, 291-311.

Bollerslev, T., R.Y. Chou, and K.F. Kroner (1992), ARCH Modeling in Finance: A Review of the Theory and Empirical Evidence, Journal of Econometrics 52, 5-59.

Campbell, J.Y. (1986), Bond and Stock Returns in a Simple Exchange Model, Quarterly Journal of Economics 101, 785-804.

Campbell, J.Y. (1991), A Variance Decomposition for Stock Returns, Economic Journal $101,157-179$.

Campbell, J.Y. (1996), Understanding Risk and Return, Journal of Political Economy 104, $298-345$. 
Campbell, J.Y. and John Ammer (1993), What Moves the Stock and Bond Markets? A Variance Decomposition for Long-Term Asset Returns, Journal of Finance 48, 3-37.

Campbell, J.Y. and J.H. Cochrane (1995), By Force of Habit: A Consumption-Based Explanation of Aggregate Stock Market Behavior, NBER Working Paper No. 4995.

Campbell, J.Y. and R.J. Shiller (1988a), The Dividend-Price Ratio and Expectations of Future Dividends and Discount Factors, Review of Financial Studies 1, 195-227.

Campbell, J.Y. and R.J. Shiller (1988b), Stock Prices, Earnings, and Expected Dividends, Journal of Finance 43, 661-676.

Cecchetti, S.G., P.-S. Lam, and N.C. Mark (1993), The Equity Premium Puzzle and the Risk-Free Rate: Matching the Moments, Journal of Monetary Economics 31, 21-45.

Chou, R.Y., R.F. Engle, and A. Kane (1992), Measuring Risk Aversion from Excess Returns on a Stock Index, Journal of Econometrics 52, 201-224.

Cochrane, J.H. (1994), Permanent and Transitory Components of GNP and Stock Prices, Quarterly Journal of Economics CIX, 241-265.

Cochrane, J.H. and L.P. Hansen (1992), Asset Pricing Lessons for Macroeconomics, in O.J. Blanchard and S. Fischer, eds., NBER Macroeconomics Annual 1992 (The MIT Press, Cambridge).

Constantinides, G. (1990), Habit Formation: A Resolution of the Equity Premium Puzzle, Journal of Political Economy 98, 519-543.

The Economist, 1987, One Hundred Years of Economic Statistics, London.

Epstein, L. and S. Zin (1991), Substitution, Risk Aversion, and the Temporal Behavior of Consumption and Asset Returns: An Empirical Investigation, Journal of Political Economy 99, 263-286. 
Fama, E.F. and K.R. French (1988a), Permanent and Temporary Components of Stock Prices, Journal of Political Economy 96, 246-273.

Fama, E.F. and K.R. French, (1988b), Dividend Yields and Expected Stock Returns, Journal of Financial Economics 22, 3-27.

Fama, E.F. and K.R. French (1989), Business Conditions and Expected Returns on Stocks and Bonds, Journal of Financial Econornics 25, 23-49.

Ferson, W.E. and G. Constantinides (1991), Habit Persistence and Durability in Aggregate Consumption: Empirical Tests, Journal of Financial Economics 29, 199-240.

Frennberg, P., and B. Hansson (1992), Computation of a Monthly Index for Swedish Stock Returns 1919-1989, Scandinavian Economic History Review 40, 3-27.

Grossman, S.J. and R.J. Shiller (1981), The Determinants of the Variability of Stock Market Prices, American Economic Review 71, 222-227.

Grossman, S.J. and Z. Zhou (1994), Equilibrium Analysis of Portfolio Insurance, unpublished paper, University of Pennsylvania.

Hansen, L.P. and R. Jagannathan (1992), Restrictions on Intertemporal Marginal Rates of Substitution Implied by Asset Returns, Journal of Political Economy 99, 225-262.

Hansen, L.P. and K.J. Singleton (1983), Stochastic Consumption, Risk Aversion, and the Temporal Behavior of Asset Returns, Journal of Political Economy 91, 249-268.

Harvey, C.R. (1989), Time-Varying Conditional Covariances in Tests of Asset Pricing Models, Journal of Financial Economics 24, 289-317.

Hassler, J., P. Lundvik, T. Persson, and P. Söderlind, 1994, "The Swedish Business Cycle: Stylized Facts Over 130 Years", in V. Bergström and A. Vredin eds. Measuring and Interpreting Business Cycles (Clarendon Press, Oxford). 
Heaton, J.C. (1995), An Empirical Investigation of Asset Pricing with Temporally Dependent Preference Specifications, Econometrica 63, 681-717.

Kandel, S. and R.F. Stambaugh (1991), Asset Returns and Intertemporal Preferences, Journal of Monetary Economics 27, 39-71.

Kocherlakota, N. (1996), The Equity Premium: It's Still A Puzzle, Journal of Economic Literature $34,42-71$.

LeRoy, S.F. and R. Porter (1981), The Present Value Relation: Tests Based on Variance Bounds, Econometrica 49, 555-577.

Lucas, R.E., Jr. (1978), Asset Prices in an Exchange Economy, Econometrica 46, 14291446.

Mankiw, N.G. and S.P. Zeldes (1991), The Consumption of Stockholders and Non-Stockholders, Journal of Financial Economics 29, 97-112.

Mehra, R. and E. Prescott (1985), The Equity Premium Puzzle, Journal of Monetary Economics 15, 145-161.

Poterba, J. and L.H. Summers (1988), Mean Reversion in Stock Returns: Evidence and Implications, Journal of Financial Economics 22, 27-60.

Ryder, H.E., Jr., and G.M. Heal (1973), Optimum Growth with Intertemporally Dependent Preferences, Review of Economic Studies 40, 1-33.

Schwert, G.W. (1989), Why Does Stock Market Volatility Change Over Time?, Journal of Finance 44, 1115-1153.

Shiller, R.J. (1981), Do Stock Prices Move Too Much to Be Justified by Subsequent Changes in Dividends?, American Economic Review 71, 421--436.

Sundaresan, S.M. (1989), Intertemporally Dependent Preferences and the Volatility of Consumption and Wealth, Review of Financial Studies 2, 73-88. 
Weil, P. (1989), The Equity Premium Puzzle and the Risk-Free Rate Puzzle, Journal of Monetary Economics 24, 401-421. 


\section{Notes for Tables}

Notes for Table 1: $V_{i}$ is the stock index market capitalization in billions of 1993 US dollars. All stock index data are from Morgan Stanley Capital International (MSCI), except for USACRSP which is from the Center for Research in Security Prices. $V_{i} / G D P_{i}$ is the index market capitalization as a percentage of 1993 GDP, $V_{i} / V_{U S M S C I}$ is the index market capitalization as a percentage of the market capitalization of the US MSCI index, and $V_{i} /\left(\sum_{i} V_{i}\right)$ is the percentage share of the index market capitalization in the total market capitalization of all the MSCI indexes. AUL denotes Australia, CAN Canada, FR France, GER Germany, ITA Italy, JAP Japan, NTH Netherlands, SP Spain, SWD Sweden, SWT Switzerland, UK United Kingdom, USA United States.

Notes for Table 2: $\overline{r_{m}}$ is the mean $\log$ real return on the market index, multiplied by 400 in quarterly data or 100 in annual data to express in annualized percentage points. $\sigma\left(r_{m}\right)$ is the standard deviation of the log real return on the market index, multiplied by 200 in quarterly data or 100 in annual data to express in annualized percentage points. $\rho\left(r_{m}\right)$ is the first-order autocorrelation of the $\log$ real return on the market index. $\overline{r_{f}}, \sigma\left(r_{f}\right)$, and $\rho\left(r_{f}\right)$ are defined in the same way for the real return on a 3 -month money market instrument. The money market instruments vary across countries and are described in detail in the Data Appendix.

Notes for Table 3: $\overline{\Delta c}$ is the mean log real consumption growth rate, multiplied by 400 in quarterly data or 100 in annual data to express in annualized percentage points. $\sigma(\Delta c)$ is the standard deviation of the log real consumption growth rate, multiplied by 200 in quarterly data or 100 in annual data to express in annualized percentage points. $\rho(\Delta c)$ is the firstorder autocorrelation of the $\log$ real consumption growth rate. $\overline{\Delta d}, \sigma(\Delta d)$, and $\rho(\Delta d)$ are defined in the same way for the real dividend growth rate. Consumption is nondurables and services consumption in the US, and total consumption elsewhere. 
Notes for Table 4: The table gives the contemporaneous cross-correlations of real consumption growth $\Delta c$, real dividend growth $\Delta d$, and the stock index return $r_{m}$, where these variables are measured at horizons of $1,4,8$, or 16 quarters in quarterly data and $1,2,4$, or 8 years in annual data. The timing convention used for consumption is that consumption measured in a given quarter corresponds to beginning-of-quarter consumption, so log consumption growth for the quarter is the log of next quarter's consumption divided by this quarter's consumption.

Notes for Table 5: $\overline{a e r_{m}}$ is the average excess log return on stock over a money market instrument, plus one half the variance of this excess return: $\overline{a e r_{m}}=\overline{r_{m}-r_{f}}+\sigma^{2}\left(r_{m}-r_{f}\right) / 2$. It is multiplied by 400 in quarterly data and 100 in annual data to express in annualized percentage points. $\sigma\left(e r_{m}\right)$ and $\sigma(\Delta c)$ are the standard deviations of the excess log return $e r_{m}=r_{m}-r_{f}$ and consumption growth $\Delta c$, respectively, multiplied by 200 in quarterly data and 100 in annual data to express in annualized percentage points. $\rho(e r, \Delta c)$ is the correlation of $e r_{m}$ and $\Delta c . \operatorname{cov}\left(e r_{m}, \Delta c\right)$ is the product $\sigma\left(e r_{m}\right) \sigma(\Delta c) \rho(e r, \Delta c) . \operatorname{RRA}(1)$ is $100 \overline{a e r_{m}} / \operatorname{cov}\left(e r_{m}, \Delta c\right)$, a measure of risk aversion calculated using the empirical covariance of excess stock returns with consumption growth. $\operatorname{RRA}(2)$ is $100 \bar{a} \bar{e} \bar{r}_{m} / \sigma\left(e r_{m}\right) \sigma(\Delta c)$, a measure of risk aversion calculated using the empirical standard deviations of excess stock returns and consumption growth, but assuming perfect correlation between these series.

Notes for Table 6: $\overline{r_{f}}$ is the mean money market return from Table 2, in annualized percentage points. $\overline{\Delta c}$ and $\sigma(\Delta c)$ are the mean and standard deviation of consumption growth from Table 3 , in annualized percentage points. RRA(1) and RRA(2) are the risk aversion coefficients from Table 5. $T P R(1)=\overline{r_{f}}-R R A(1) \overline{\Delta c}+R R A(1)^{2} \sigma^{2}(\Delta c) / 200$, and $T P R(2)=\overline{r_{f}}-R R A(2) \overline{\Delta c}+R R A(2)^{2} \sigma^{2}(\Delta c) / 200$. These time preference rates give the real interest rate, in annualized percentage points, that would prevail if consumption growth had zero mean and zero standard deviation and risk aversion were RRA(1) or RRA(2), respectively. 
Notes for Table 7: $\overline{P / D}$ is the mean price-dividend ratio. $\sigma(p-d)$ is the standard deviation of the log price-dividend ratio in natural units (not annualized percentage points). $\rho(p-d)$ is the first-order autocorrelation of the $\log$ price-dividend ratio. $\operatorname{ADF}(1)$ is the augmented Dickey-Fuller t-ratio for the lagged log price-dividend ratio when the change in the $\log$ price-dividend ratio is regressed on a constant, four lagged changes, and the lagged $\log$ price-dividend ratio. $\left(^{*}\right)$ indicates a rejection of the unit root hypothesis for the $\log$ price-dividend ratio at the $5 \%$ level. $\overline{\Delta p}, \overline{\Delta d}$, and $\overline{\Delta p-\bar{d}}$ are the mean changes in log prices, $\log$ dividends, and the $\log$ price-dividend ratio respectively.

Notes for Table 8: The table reports regression coefficients $\hat{\beta}(k)$, t-statistics $t(\hat{\beta}(k))$, and $R^{2}$ statistics $R^{2}(k)$ for regressions whose dependent variables are real consumption growth, real dividend growth, real returns on 3-month money market instruments, or excess returns on stock over money market instruments, all measured in natural units (not annualized percentage points) at horizons $k$ of 4,8 , or 16 quarters in quarterly data or 1,4 , or 8 years in annual data. The independent variable in every regression is the log price-dividend ratio, normalized by dividing by its standard deviation. The $t$-statistics are corrected for heteroskedasticity and serial correlation in the equation errors using the Newey-West method.

Notes for Table 9: The table reports regression coefficients $\hat{\beta}(k)$, t-statistics $t(\hat{\beta}(k))$, and $R^{2}$ statistics $R^{2}(k)$ for regressions whose dependent variables are real consumption growth, real dividend growth, real returns on 3-month money market instruments, or excess returns on stock over money market instruments, all measured at horizons $k$ of 4,8 , or 16 quarters in quarterly data or 1,4 , or 8 years in annual data. The independent variable in every regression is stochastically detrended log consumption, normalized by dividing by its standard deviation. Stochastically detrended log consumption is the difference between log consumption $c_{t}$ and a "habit" measure $x_{t}$, constructed from $x_{t}=g+\varphi x_{t-1}+(1-\varphi) c_{t-1}$, where $x=c$ at the first date in the sample. $\varphi=0.97$ in quarterly data and $0.97^{4}$ in annual data. The $t$-statistics are corrected for heteroskedasticity and serial correlation in the equation errors using the Newey-West method. 
Notes for Figures 1a, 2a, and 3a: The figures show log consumption as a solid line and the stochastic trend in log consumption as a dashed line. The stochastic trend in log consumption is constructed as $x_{t}=g+\varphi x_{t-1}+(1-\varphi) c_{t-1}$, where $x=c$ at the first date in the sample and $\varphi=0.97^{4}$. Stochastically detrended $\log$ consumption is the difference between the two lines. Figure 1a uses Swedish annual data, figure 2a uses UK annual data, and figure 3a uses US annual data.

Notes for Figures $1 \mathrm{~b}, 2 \mathrm{~b}$, and $3 \mathrm{~b}$ : The figures show the $\log$ price-dividend ratio as a solid line and stochastically detrended log consumption as a dashed line. The two series are normalized so that they both have zero mean and unit standard deviation. Figure $1 \mathrm{~b}$ uses Swedish annual data, figure $2 b$ uses UK annual data, and figure $3 \mathrm{~b}$ uses US annual data. 
TABLE 1

MSCI MARKET CAPITALIZATION

1993

\begin{tabular}{l|cccc}
\multicolumn{1}{c|}{ Country } & \multicolumn{1}{c}{$V_{i}$} & $V_{i} / G D P_{i}$ & $V_{i} / V_{U S M S C I}$ & $V_{i} /\left(\sum_{i} V_{i}\right)$ \\
& (Bill. of US\$) & $\%$ & $\%$ & $\%$ \\
\hline AUL & 117.9 & 41.55 & 4.65 & 1.85 \\
CAN & 167.3 & 30.62 & 6.60 & 2.63 \\
FR & 272.5 & 22.49 & 10.75 & 4.29 \\
GER & 280.7 & 16.83 & 11.07 & 4.41 \\
ITA & 86.8 & 9.45 & 3.42 & 1.37 \\
JAP & 1651.9 & 39.74 & 65.16 & 25.98 \\
NTH & 136.7 & 45.91 & 5.39 & 2.15 \\
SP & 81.2 & 18.64 & 3.20 & 1.28 \\
SWD & 62.9 & 36.22 & 2.48 & 0.99 \\
SWT & 205.6 & 87.46 & 8.12 & 3.23 \\
UK & 758.4 & 79.52 & 29.91 & 11.93 \\
USA-MSCI & 2535.3 & 37.25 & 100.00 & 39.88 \\
USA-CRSP & 4875.6 & 71.64 & 192.30 & \\
\hline
\end{tabular}


TABLE 2

INTERNATIONAL STOCK AND BILL RETURNS

\begin{tabular}{lc|ccc|ccc} 
Country & Sample Period & $\overline{r_{m}}$ & $\sigma\left(r_{m}\right)$ & $\rho\left(r_{m}\right)$ & $\overline{r_{f}}$ & $\sigma\left(r_{f}\right)$ & $\rho\left(r_{f}\right)$ \\
\hline AUL & $1970.1-1994.3$ & 2.526 & 24.350 & 0.008 & 1.676 & 2.685 & 0.636 \\
CAN & $1970.1-1994.3$ & 3.892 & 17.294 & 0.119 & 2.630 & 1.989 & 0.674 \\
FR & $1970.2-1994.3$ & 6.620 & 23.090 & 0.063 & 2.601 & 1.892 & 0.733 \\
GER & $1978.4-1994.3$ & 7.633 & 21.271 & 0.077 & 3.450 & 1.213 & 0.313 \\
ITA & $1971.2-1993.3$ & 0.380 & 28.110 & 0.071 & 1.876 & 3.035 & 0.694 \\
JAP & $1970.1-1993.4$ & 5.828 & 22.126 & 0.007 & 1.497 & 2.477 & 0.485 \\
NTH & $1977.2-1994.3$ & 11.900 & 16.215 & 0.024 & 3.790 & 1.515 & -0.010 \\
SP & $1974.2-1993.3$ & -1.543 & 26.505 & 0.010 & 1.519 & 4.017 & 0.511 \\
SWD & $1970.1-1994.2$ & 7.948 & 24.216 & 0.053 & 1.422 & 3.054 & 0.186 \\
SWT & $1975.4-1994.3$ & 7.325 & 18.872 & -0.093 & 0.508 & 1.828 & 0.451 \\
UK & $1970.1-1994.3$ & 6.672 & 22.349 & 0.102 & 0.838 & 3.191 & 0.457 \\
USA & $1970.1-1993.4$ & 4.974 & 18.177 & 0.065 & 1.307 & 1.802 & 0.582 \\
\hline USA & $1947.2-1993.4$ & 7.205 & 15.815 & 0.098 & 0.737 & 1.800 & 0.506 \\
\hline SWD & $1919-1993$ & 5.795 & 19.126 & 0.099 & 1.901 & 6.111 & 0.652 \\
UK & $1919-1993$ & 7.506 & 22.766 & -0.018 & 1.185 & 5.482 & 0.590 \\
USA & $1890-1992$ & 6.429 & 18.699 & 0.025 & 1.987 & 9.017 & 0.343 \\
\hline
\end{tabular}


TABLE 3

\section{INTERNATIONAL CONSUMPTION AND DIVIDENDS}

\begin{tabular}{lc|ccc|ccc} 
Country & Sample Period & $\overline{\Delta c}$ & $\sigma(\Delta c)$ & $\rho(\Delta c)$ & $\overline{\Delta d}$ & $\sigma(\Delta d)$ & $\rho(\Delta d)$ \\
\hline AUL & $1970.1-1994.3$ & 1.862 & 2.292 & -0.355 & 0.478 & 37.573 & -0.452 \\
CAN & $1970.1-1994.3$ & 2.001 & 2.256 & 0.023 & -1.242 & 5.927 & 0.532 \\
FR & $1970.2-1994.3$ & 1.981 & 2.142 & -0.057 & -1.158 & 13.161 & -0.153 \\
GER & $1978.4-1994.3$ & 1.639 & 2.614 & -0.330 & 0.225 & 8.813 & -0.003 \\
ITA & $1971.2-1993.3$ & 2.459 & 1.805 & 0.308 & -5.688 & 20.027 & 0.312 \\
JAP & $1970.1-1993.4$ & 3.581 & 1.983 & -0.056 & -2.411 & 4.604 & 0.349 \\
NTH & $1977.2-1994.3$ & 1.568 & 2.507 & -0.087 & 3.419 & 5.013 & 0.272 \\
SP & $1974.2-1993.3$ & 1.432 & 1.918 & 0.421 & -6.821 & 7.126 & 0.008 \\
SWD & $1970.1-1994.2$ & 0.710 & 1.949 & -0.304 & 0.838 & 12.686 & 0.403 \\
SWT & $1975.4-1994.3$ & 0.790 & 2.766 & -0.308 & 2.092 & 10.322 & -0.257 \\
UK & $1970.1-1994.3$ & 1.962 & 2.688 & -0.015 & 0.060 & 7.320 & 0.320 \\
USA & $1970.1-1993.4$ & 1.604 & 0.930 & 0.388 & 0.086 & 15.157 & -0.656 \\
\hline USA & $1947.2-1993.4$ & 1.777 & 1.113 & 0.196 & 2.059 & 28.968 & -0.556 \\
\hline SWD & $1919-1993$ & 1.976 & 3.248 & 0.175 & 0.283 & 12.178 & 0.265 \\
UK & $1919-1993$ & 1.431 & 2.916 & 0.276 & 1.808 & 8.014 & 0.230 \\
USA & $1890-1992$ & 1.720 & 3.317 & -0.126 & 1.484 & 14.300 & -0.089 \\
\hline
\end{tabular}




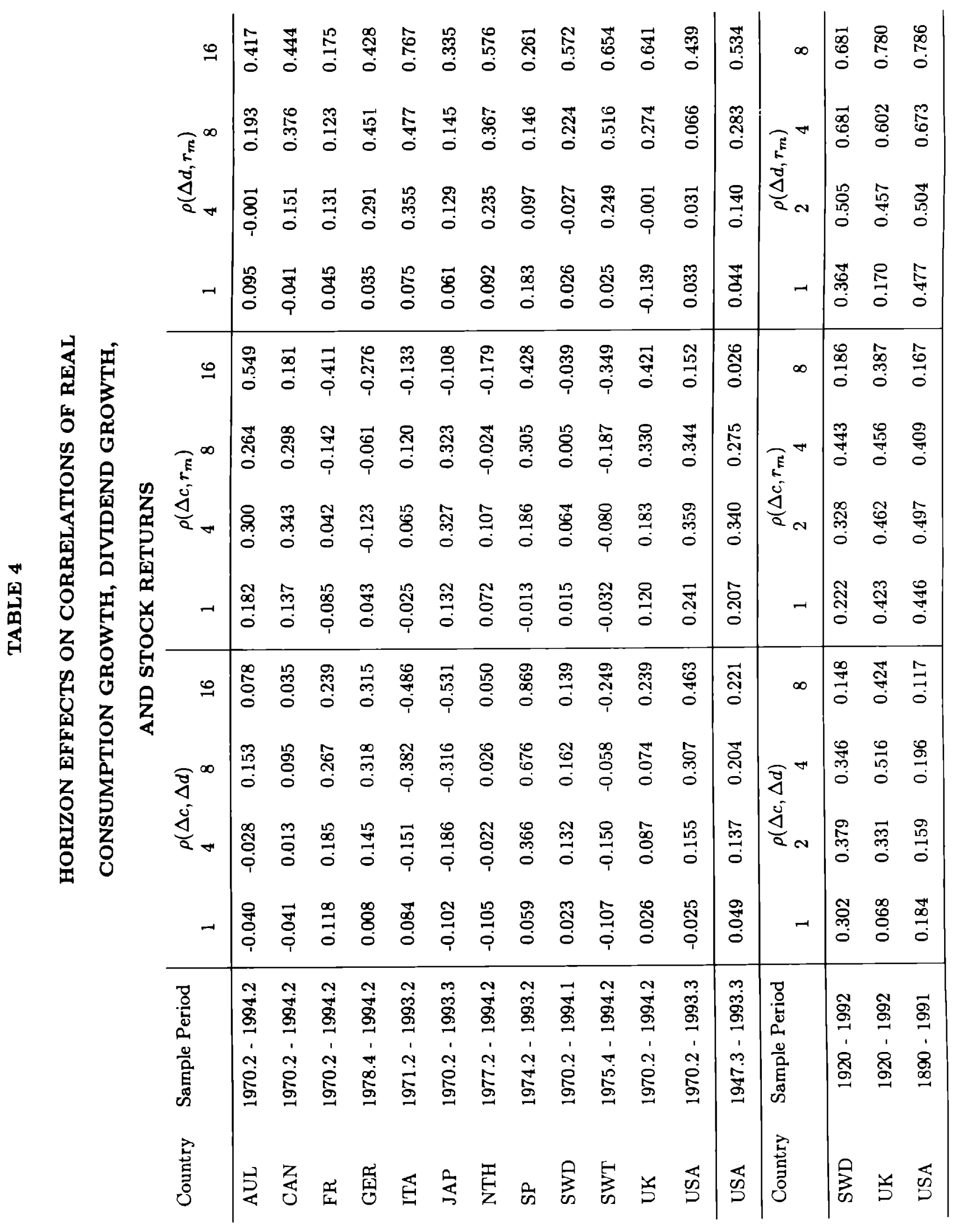


TABLE 5

THE EQUITY PREMIUM PUZZLE IN INTERNATIONAL DATA

\begin{tabular}{lc|c|ccc|c|cr} 
Country & Sample Period & $\overline{a e r_{m}}$ & $\sigma\left(e r_{m}\right)$ & $\sigma(\Delta c)$ & $\rho(e r, \Delta c)$ & $\operatorname{cov}\left(e r_{m}, \Delta c\right)$ & RRA(1) & RRA $(2)$ \\
\hline AUL & $1970.1-1994.2$ & 3.687 & 24.080 & 2.295 & 0.163 & 9.025 & 40.858 & 6.674 \\
CAN & $1970.1-1994.2$ & 2.439 & 17.209 & 2.207 & 0.154 & 5.849 & 41.689 & 6.421 \\
FR & $1970.2-1994.2$ & 6.763 & 23.060 & 2.153 & -0.075 & -3.712 & $<0$ & 13.619 \\
GER & $1978.4-1994.2$ & 6.596 & 21.331 & 2.634 & 0.044 & 2.480 & 265.960 & 11.738 \\
ITA & $1971.2-1993.2$ & 2.100 & 28.172 & 1.758 & -0.005 & -0.225 & $<0$ & 4.240 \\
JAP & $1970.1-1993.3$ & 7.181 & 21.689 & 1.951 & 0.129 & 5.463 & 131.442 & 16.972 \\
NTH & $1977.2-1994.2$ & 9.368 & 16.189 & 2.377 & 0.067 & 2.578 & 363.328 & 24.344 \\
SP & $1974.2-1993.2$ & -0.309 & 25.668 & 1.931 & -0.020 & -0.986 & 31.310 & 0 \\
SWD & $1970.1-1994.1$ & 9.537 & 23.892 & 1.945 & 0.004 & 0.167 & 5699.045 & 20.520 \\
SWT & $1975.4-1994.2$ & 8.852 & 18.726 & 2.622 & -0.021 & -1.013 & $<0$ & 18.027 \\
UK & $1970.1-1994.2$ & 8.282 & 22.413 & 2.696 & 0.091 & 5.500 & 150.583 & 13.705 \\
USA & $1970.1-1993.3$ & 5.245 & 17.842 & 0.933 & 0.233 & 3.878 & 135.255 & 31.505 \\
\hline USA & $1947.2-1993.3$ & 7.693 & 15.597 & 1.110 & 0.183 & 3.166 & 243.014 & 44.445 \\
\hline SWD & $1919-1992$ & 5.207 & 18.721 & 2.886 & 0.155 & 8.385 & 62.108 & 9.637 \\
UK & $1919-1992$ & 8.525 & 21.802 & 2.842 & 0.352 & 21.833 & 39.048 & 13.761 \\
USA & $1890-1991$ & 6.211 & 18.768 & 3.302 & 0.485 & 30.079 & 20.650 & 10.023 \\
\hline
\end{tabular}




\section{TABLE 6}

THE RISKFREE RATE PUZZLE IN INTERNATIONAL DATA

\begin{tabular}{|c|c|c|c|c|c|c|c|c|}
\hline Country & Sample Period & $\overline{r_{f}}$ & $\overline{\Delta c}$ & $\sigma(\Delta c)$ & RRA(1) & TPR(1) & RRA(2) & TPR(2) \\
\hline AUL & $1970.1-1994.2$ & 1.676 & 1.821 & 2.295 & 40.858 & -28.770 & 6.674 & -9.303 \\
\hline CAN & $1970.1-1994.2$ & 2.630 & 2.105 & 2.207 & 41.689 & -42.822 & 6.421 & -9.885 \\
\hline FR & $1970.2-1994.2$ & 2.601 & 1.981 & 2.153 & $<$ & N/A & 13.619 & -20.078 \\
\hline GER & $1978.4-1994.2$ & 3.450 & 1.622 & 2.634 & 265.960 & 2026.775 & 11.738 & -10.804 \\
\hline ITA & $1971.2-1993.2$ & 1.876 & 2.554 & 1.758 & $<$ & $\mathrm{N} / \mathrm{A}$ & 4.240 & -8.676 \\
\hline JAP & $1970.1-1993.3$ & 1.497 & 3.497 & 1.951 & 131.442 & -129.418 & 16.972 & -52.378 \\
\hline NTH & $1977.2-1994.2$ & 3.790 & 1.365 & 2.377 & 363.328 & 3236.598 & 24.344 & -12.708 \\
\hline SP & $1974.2-1993.2$ & 1.519 & 1.427 & 1.931 & 31.310 & -24.899 & $<0$ & N/A \\
\hline SWD & $1970.1-1994.1$ & 1.422 & 0.755 & 1.945 & 5699.04561 & 10228.713 & 20.520 & -6.112 \\
\hline SW'T & $1975.4-1994.2$ & 0.508 & 1.004 & 2.622 & $<$ & N/A & 18.027 & -6.414 \\
\hline UK & $1970.1-1994.2$ & 0.838 & 1.998 & 2.696 & 150.583 & 523.998 & 13.705 & -19.720 \\
\hline USA & $1970.1-1993.3$ & 1.307 & 1.592 & 0.933 & 135.255 & -134.408 & 31.505 & -44.537 \\
\hline USA & $1947.2-1993.3$ & 0.737 & 1.760 & 1.110 & 243.014 & -63.375 & 44.445 & -65.335 \\
\hline SWD & $1919-1992$ & 1.901 & 1.799 & 2.886 & 62.108 & 50.834 & 9.637 & -11.569 \\
\hline UK & $1919-1992$ & 1.185 & 1.346 & 2.842 & 39.048 & 10.176 & 13.761 & -9.695 \\
\hline USA & $1890-1991$ & 1.987 & 1.765 & 3.302 & 20.650 & -11.220 & 10.023 & -10.229 \\
\hline
\end{tabular}




\section{TABLE 7}

\section{INTERNATIONAL STOCK PRICES AND DIVIDENDS}

\begin{tabular}{|c|c|c|c|c|c|c|c|c|}
\hline Country & Sample Period & $\overline{P / D}$ & $\sigma(p-d)$ & $\rho(p-d)$ & $\operatorname{ADF}(1)$ & $\overline{\Delta p}$ & $\overline{\Delta d}$ & $\overline{\Delta p-d}$ \\
\hline AUL & $1970.1-1994.3$ & 25.821 & 0.276 & 0.852 & $-3.126^{*}$ & -1.537 & 0.478 & -2.037 \\
\hline CAN & $1970.1-1994.3$ & 29.132 & 0.203 & 0.882 & -2.319 & 0.013 & -1.242 & 0.871 \\
\hline FR & $1970.2-1994.3$ & 21.328 & 0.514 & 0.968 & -1.310 & 0.525 & -1.158 & 1.851 \\
\hline GER & $1978.4-1994.3$ & 26.739 & 0.296 & 0.914 & -1.631 & 3.547 & 0.225 & 4.060 \\
\hline ITA & $1971.2-1993.3$ & 39.716 & 0.305 & 0.871 & $-3.652^{*}$ & -2.395 & -5.688 & 3.031 \\
\hline JAP & $1970.1-1993.4$ & 86.105 & 0.652 & 0.971 & -1.763 & 4.140 & -2.411 & 6.029 \\
\hline NTH & $1977.2-1994.3$ & 20.234 & 0.253 & 0.928 & -0.937 & 6.544 & 3.419 & 3.108 \\
\hline SP & $1974.2-1993.3$ & 17.588 & 0.509 & 0.938 & -1.505 & -8.848 & -6.821 & -2.403 \\
\hline SWD & $1970.1-1994.2$ & 33.776 & 0.417 & 0.923 & -1.390 & 4.875 & 0.838 & 4.326 \\
\hline SWT & $1975.4-1994.3$ & 41.582 & 0.200 & 0.872 & -1.522 & 4.792 & 2.092 & 2.474 \\
\hline UK & $1970.1-1994.3$ & 18.025 & 0.279 & 0.906 & -1.695 & 0.782 & 0.060 & 0.459 \\
\hline USA & $1970.1-1993.4$ & 26.654 & 0.212 & 0.894 & -1.852 & 0.980 & 0.086 & 0.923 \\
\hline USA & $1947.2-1993.4$ & 26.435 & 0.254 & 0.943 & -2.008 & 3.102 & 2.059 & 1.356 \\
\hline SWD & $1919-1993$ & 26.113 & 0.319 & 0.721 & -0.903 & 2.160 & 0.283 & 1.877 \\
\hline UK & $1919-1993$ & 20.756 & 0.239 & 0.503 & $-4.042^{*}$ & 2.242 & 1.808 & 0.435 \\
\hline USA & $1890-1992$ & 22.305 & 0.266 & 0.768 & -2.241 & 1.741 & 1.484 & 0.385 \\
\hline
\end{tabular}




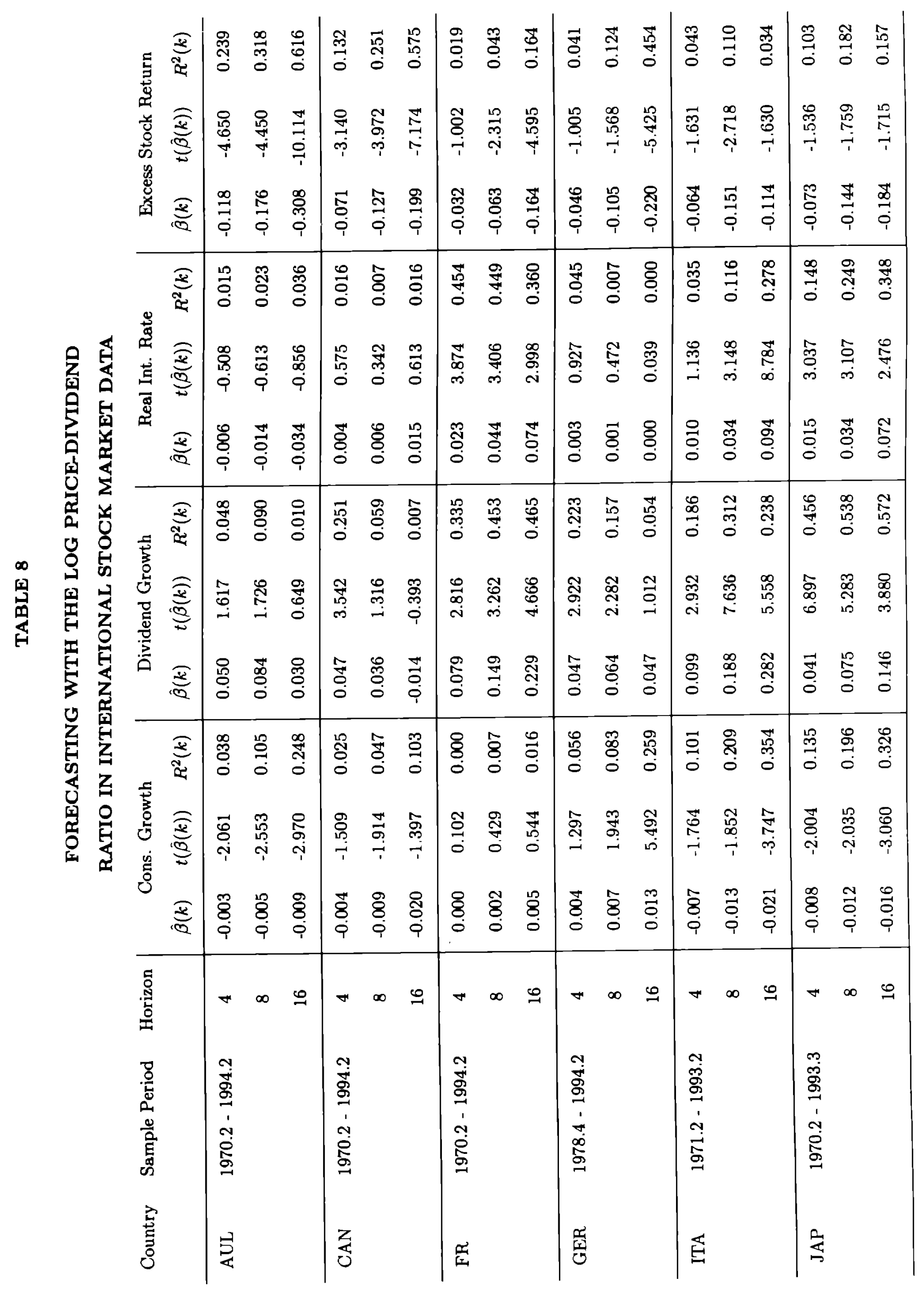




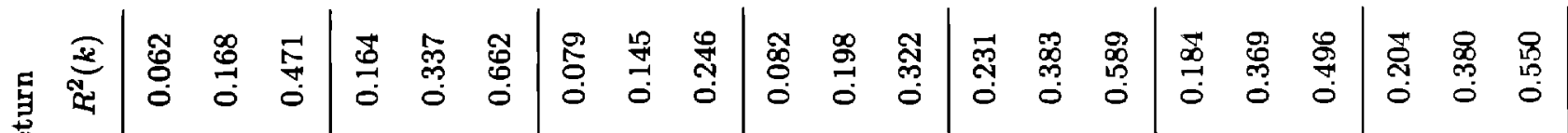

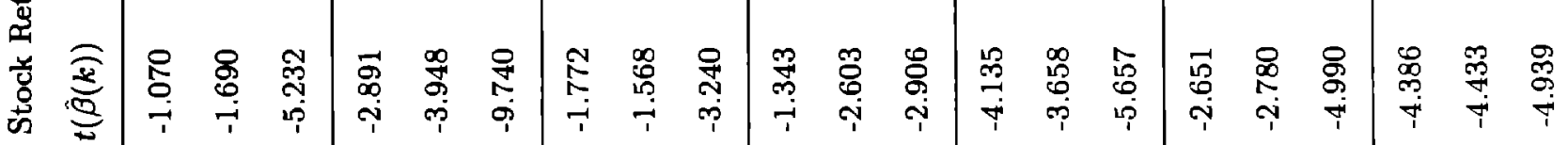

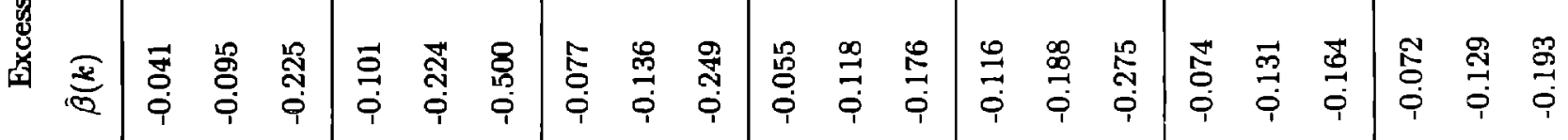

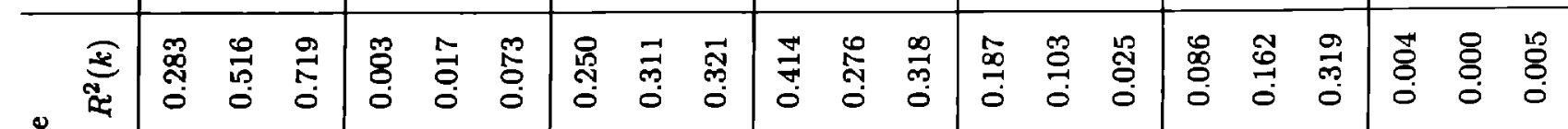

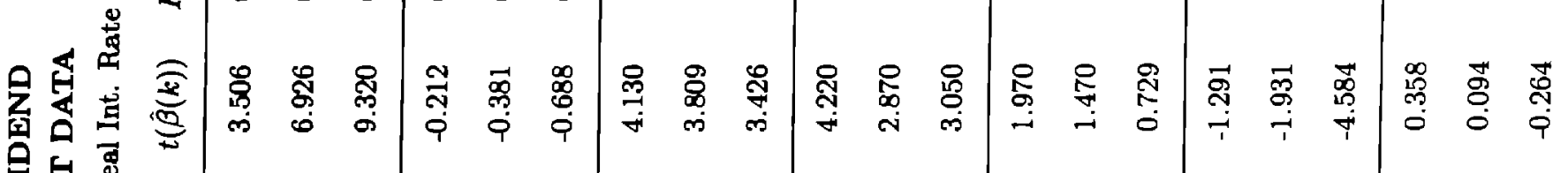

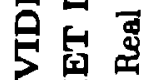
硡 要 蛋

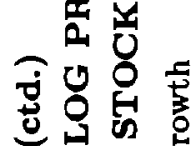

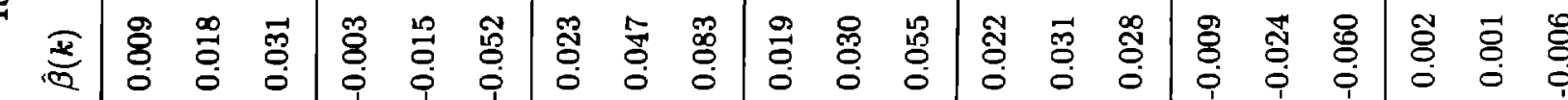

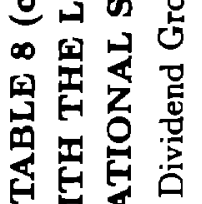

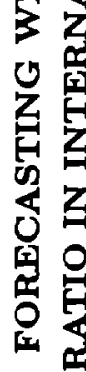

₹

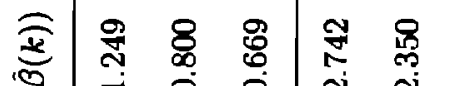

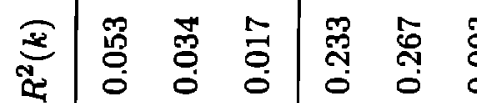

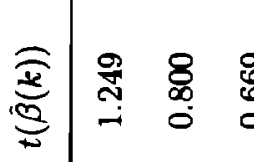

窎

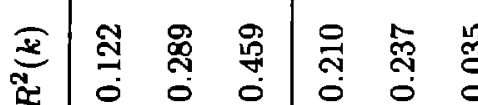

ลิ (

용

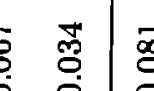

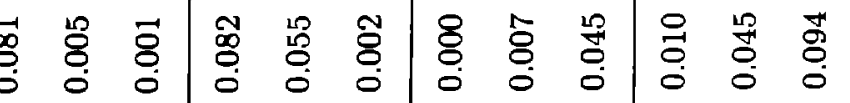
2

I

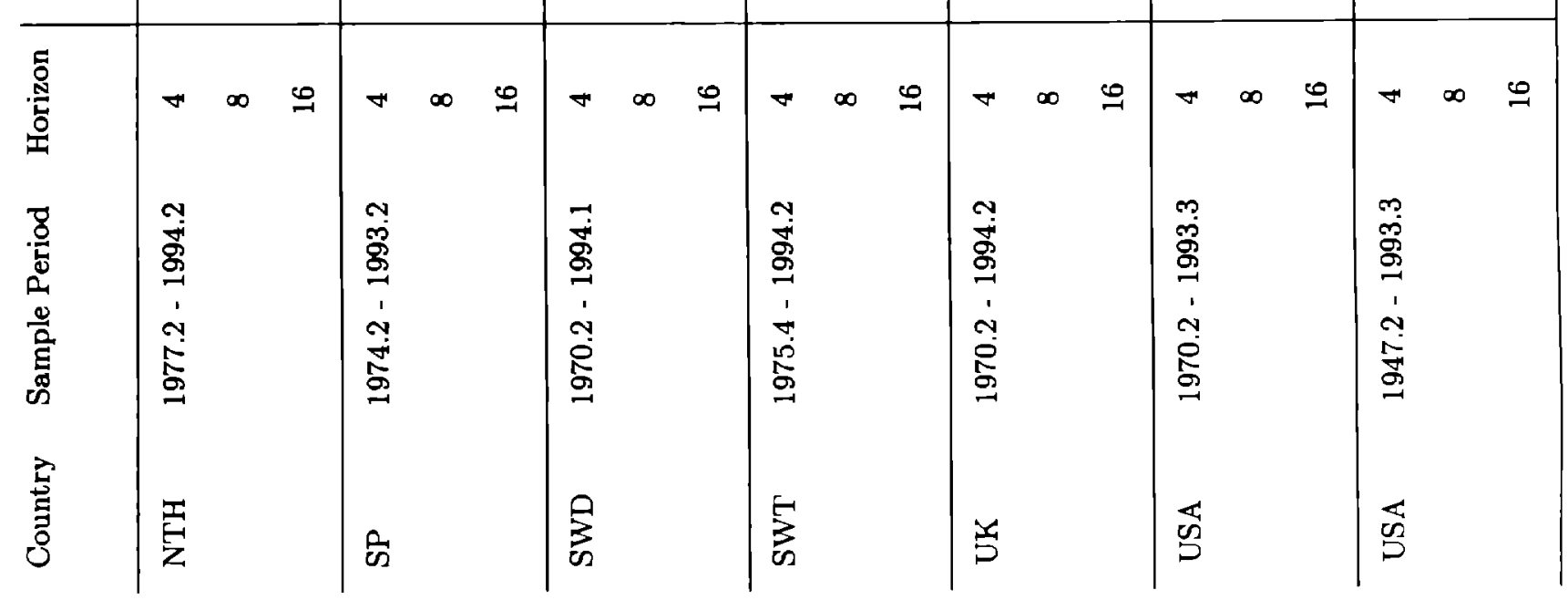




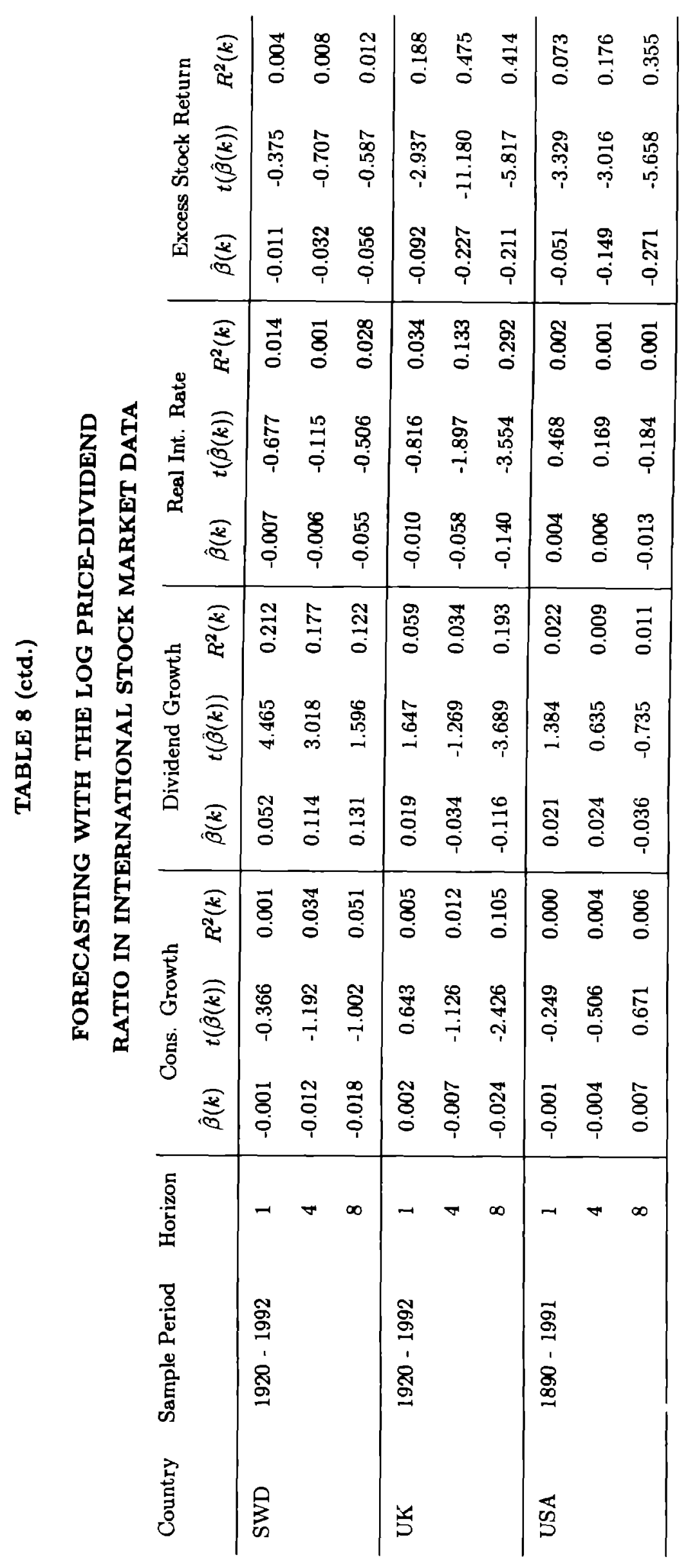




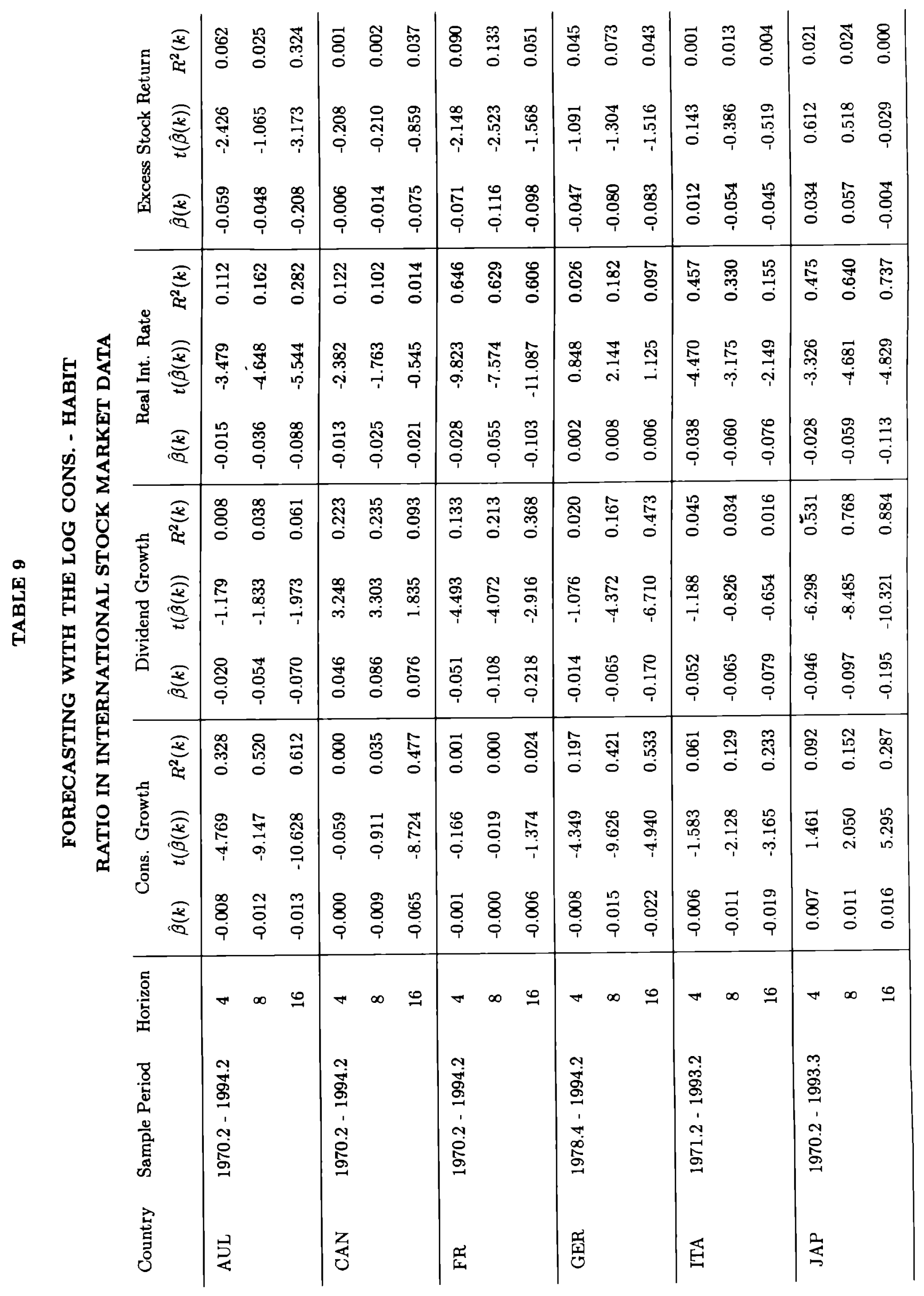




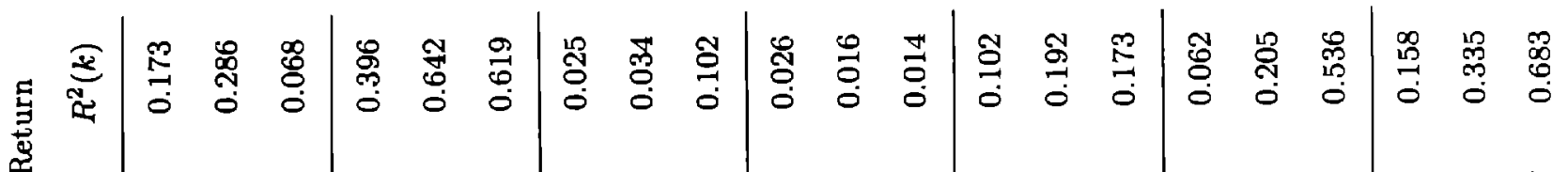

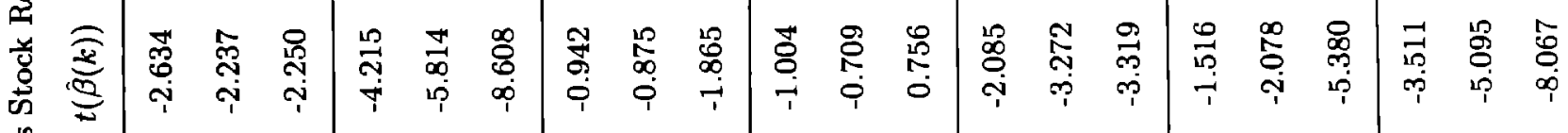
兽

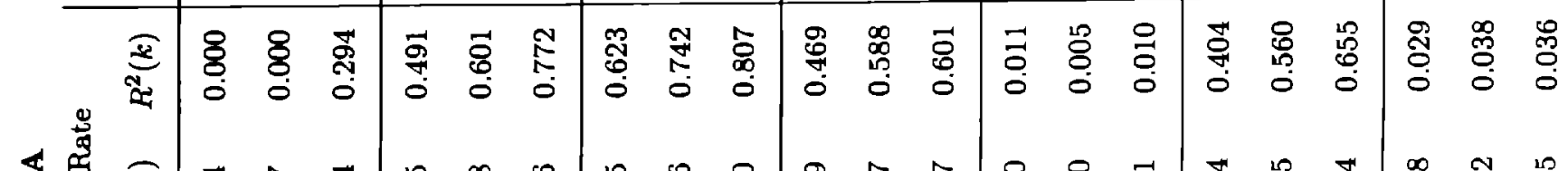

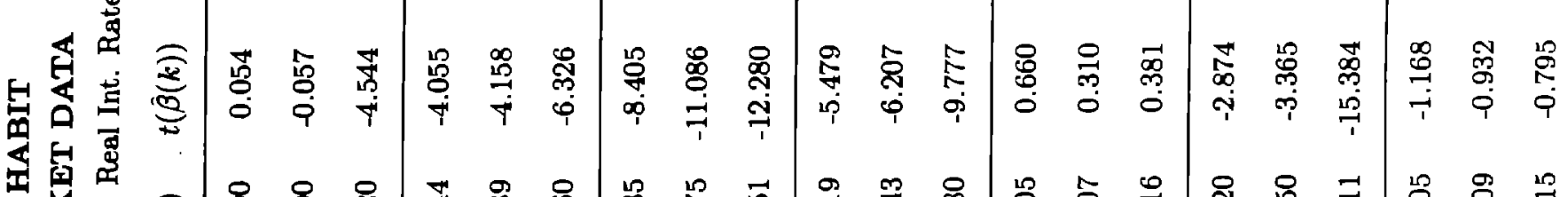
政 (⿻一,

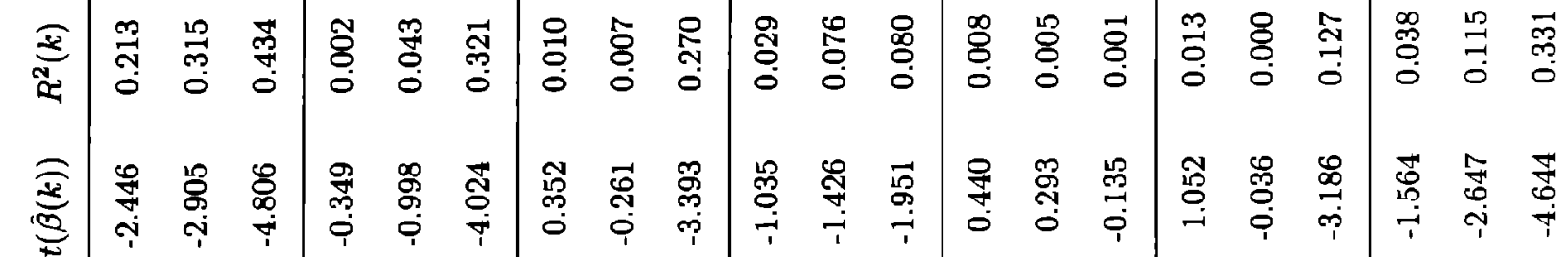
突赑

8

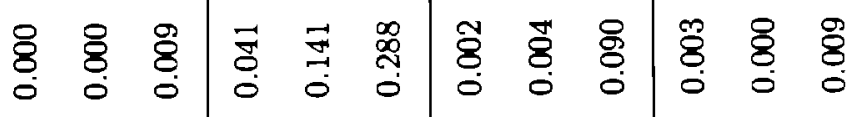

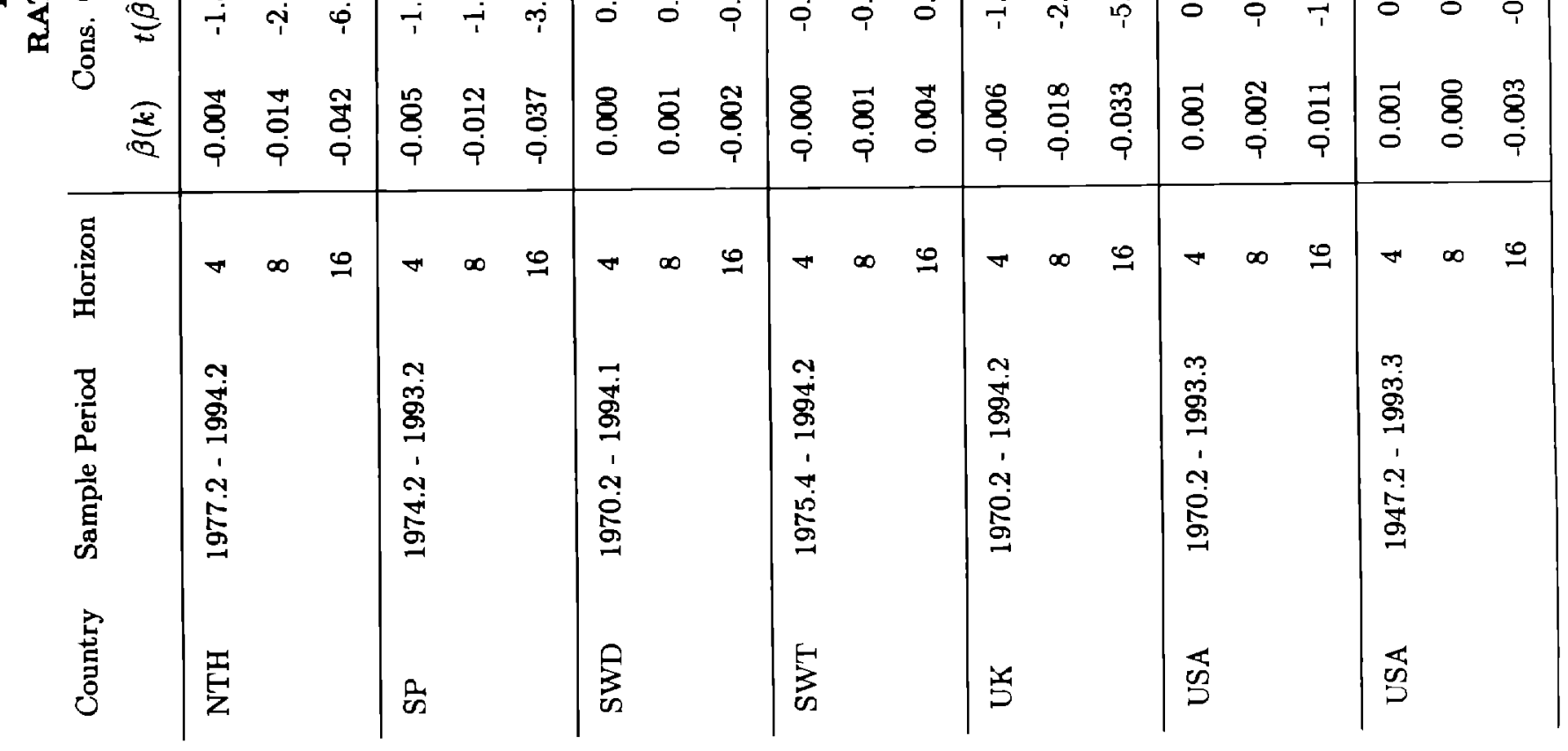




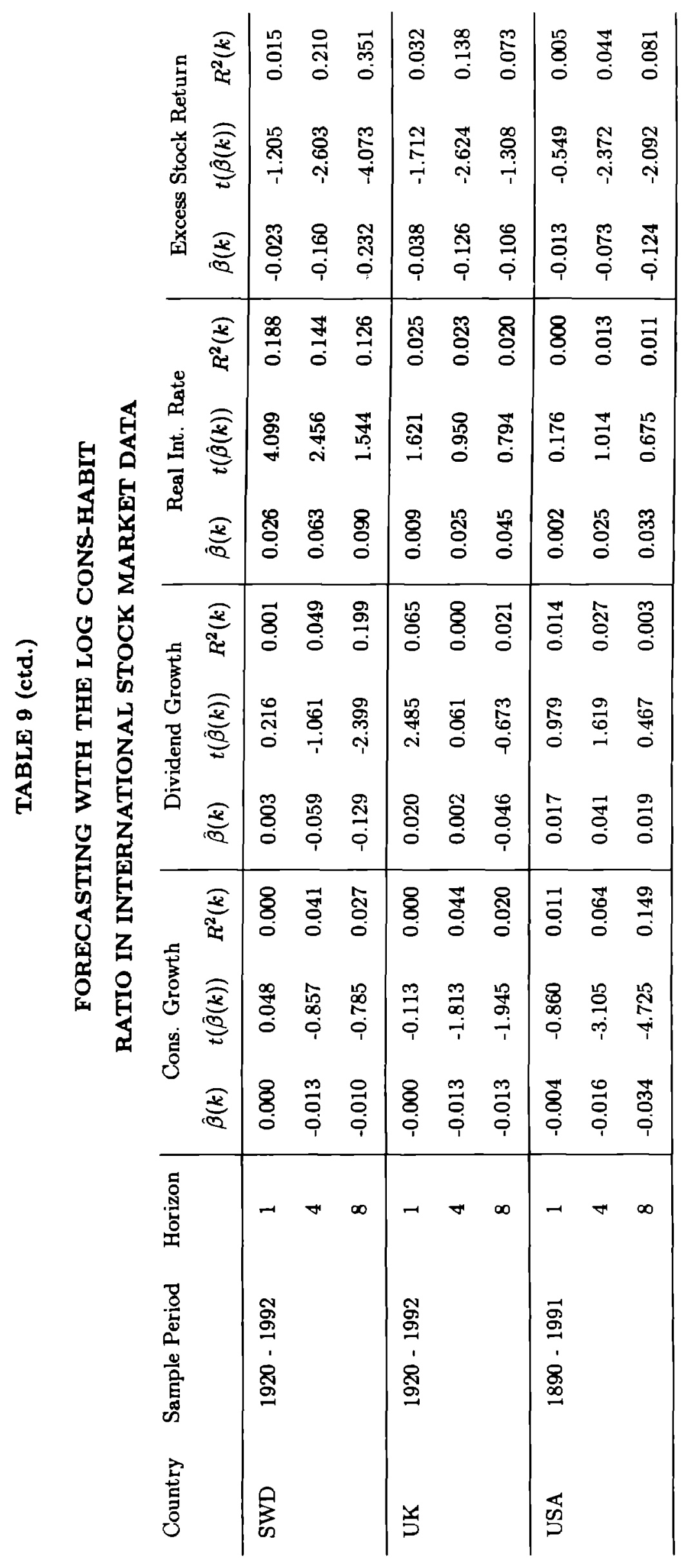




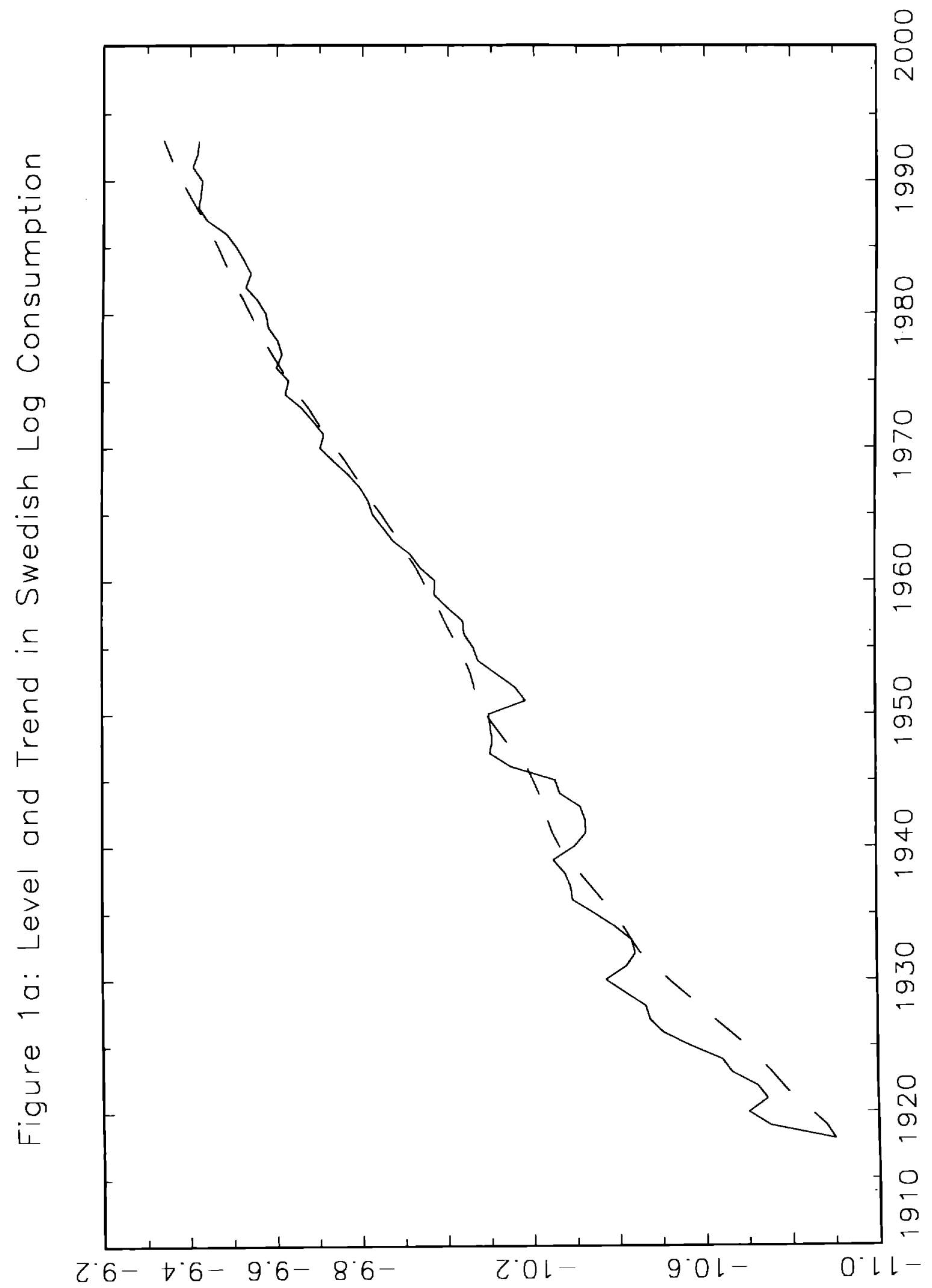




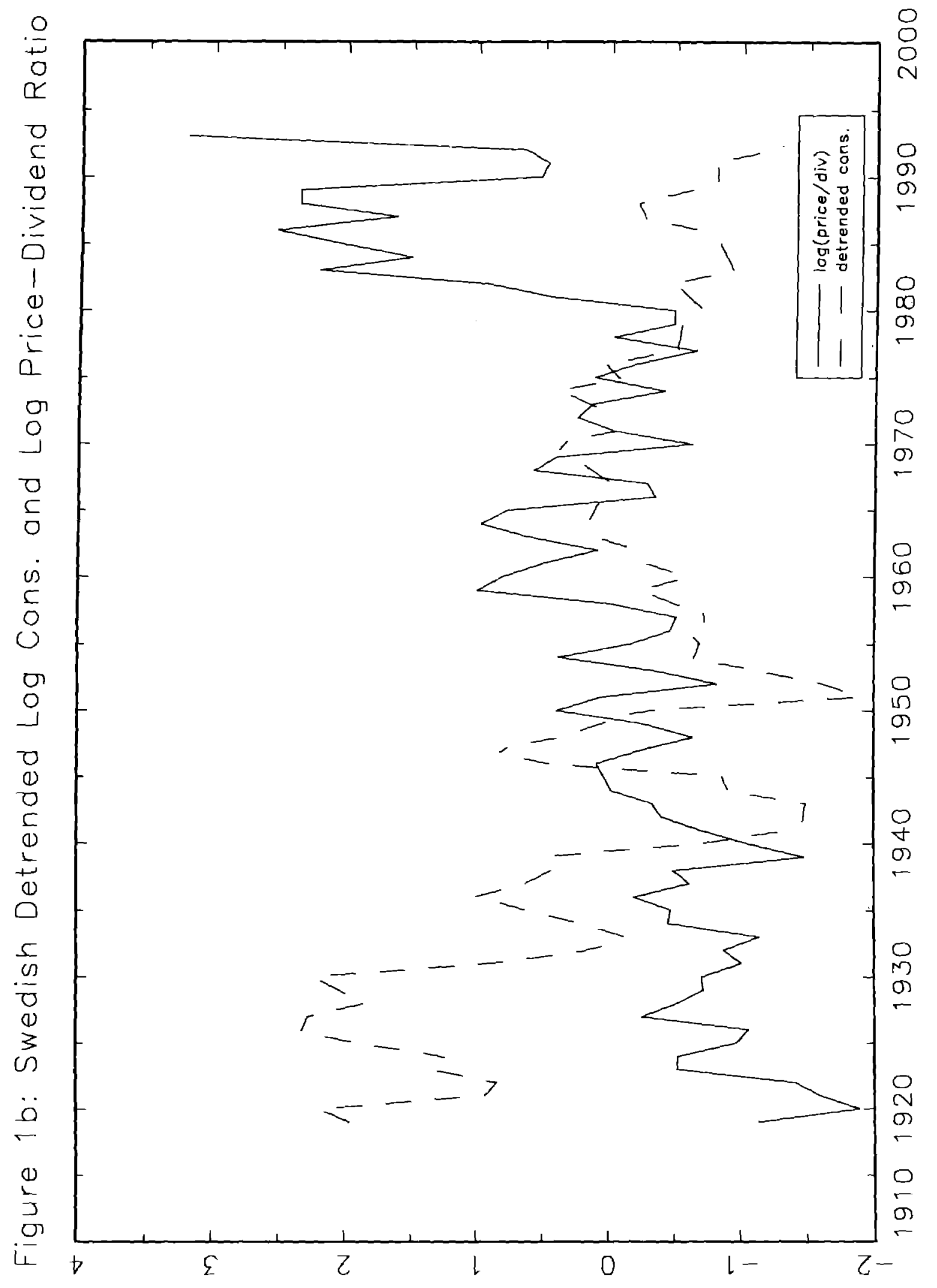




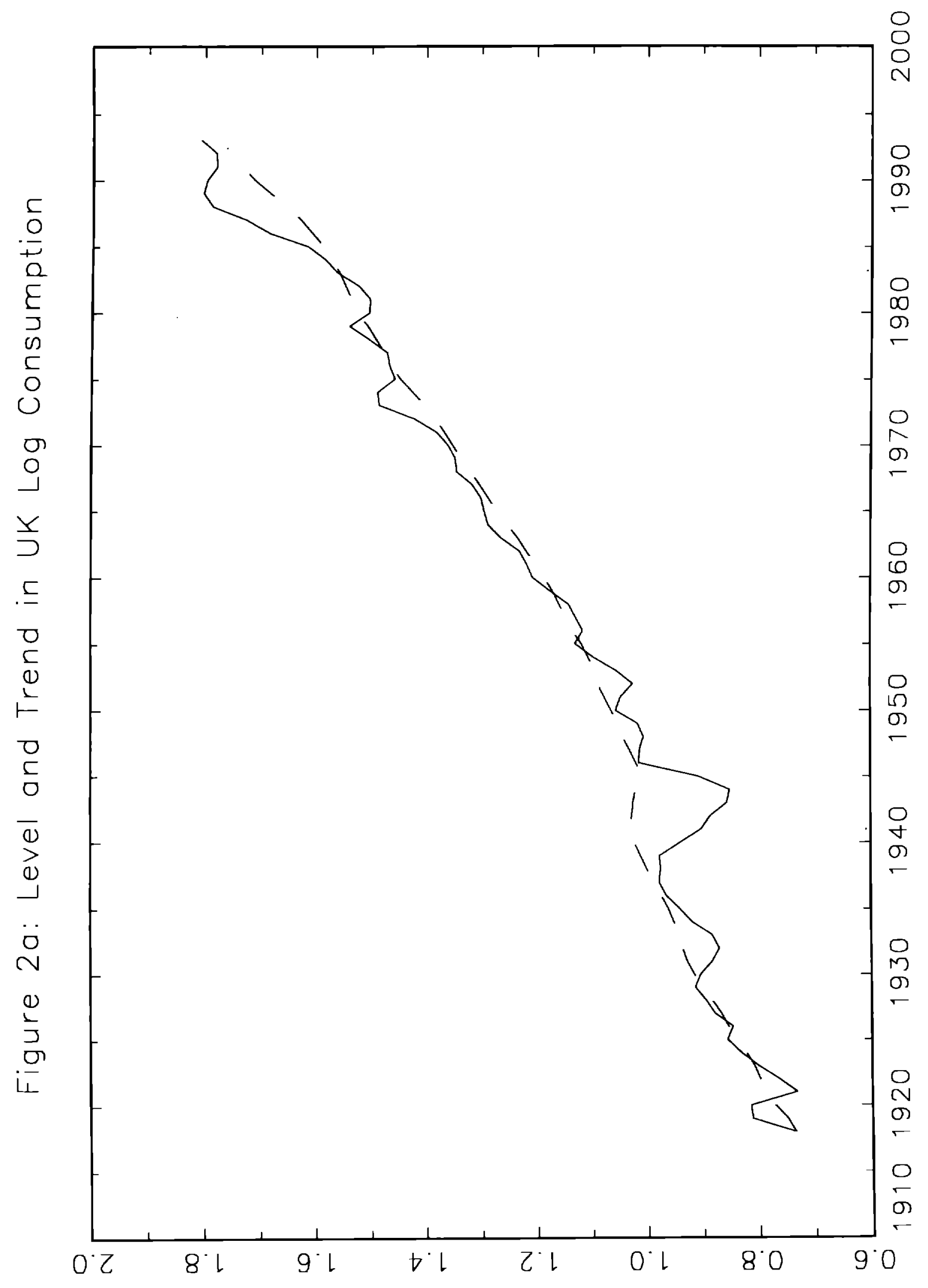




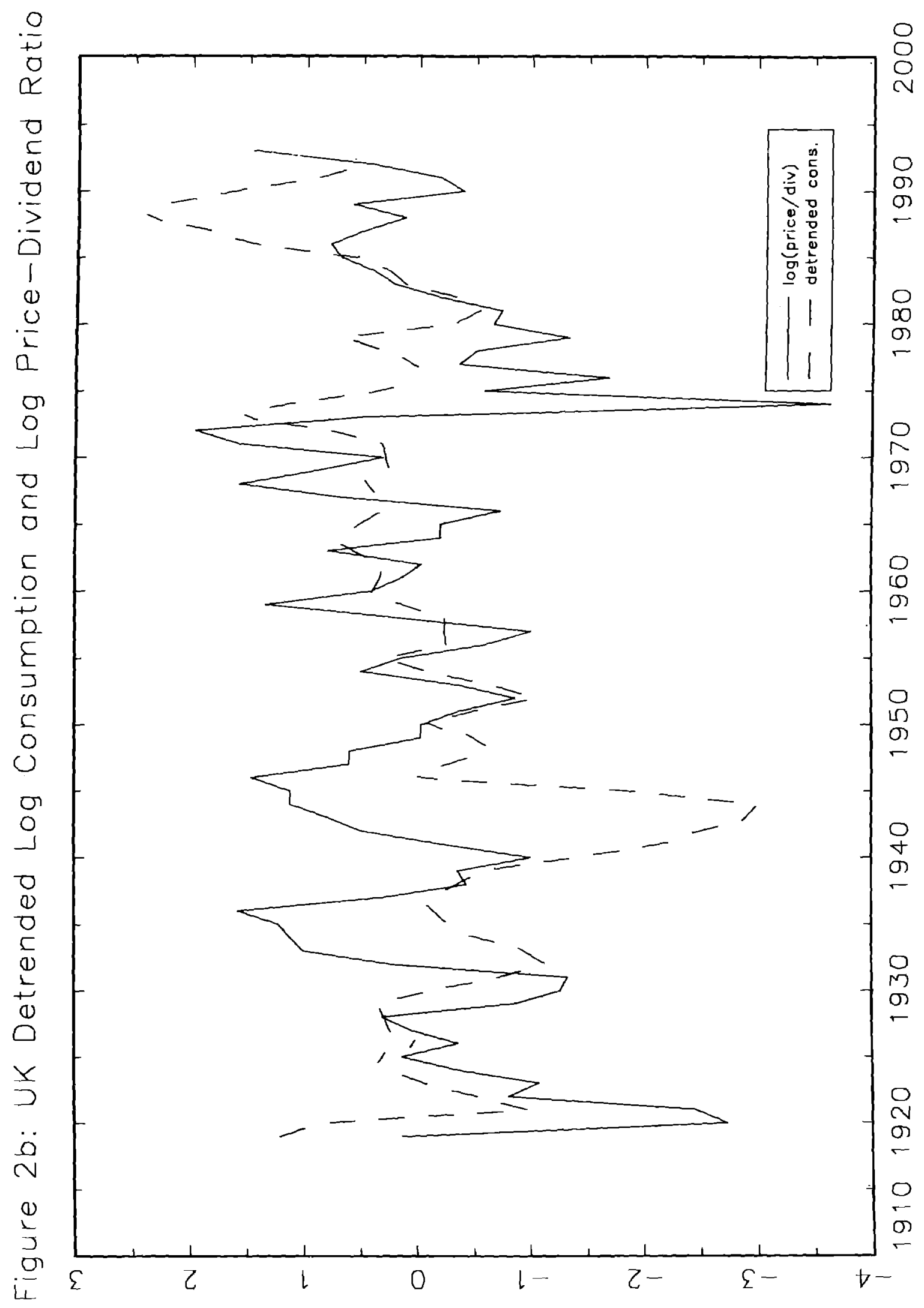




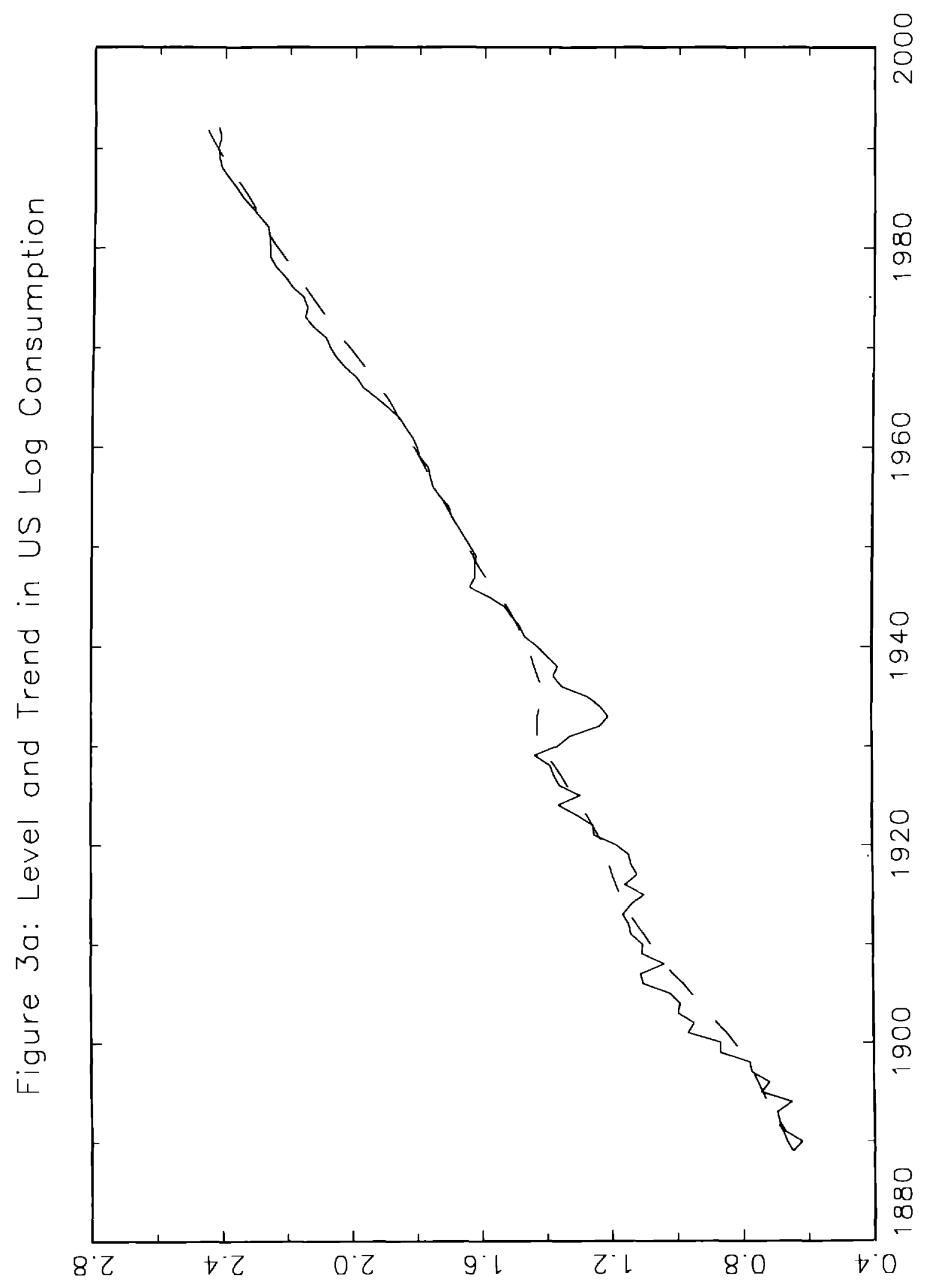




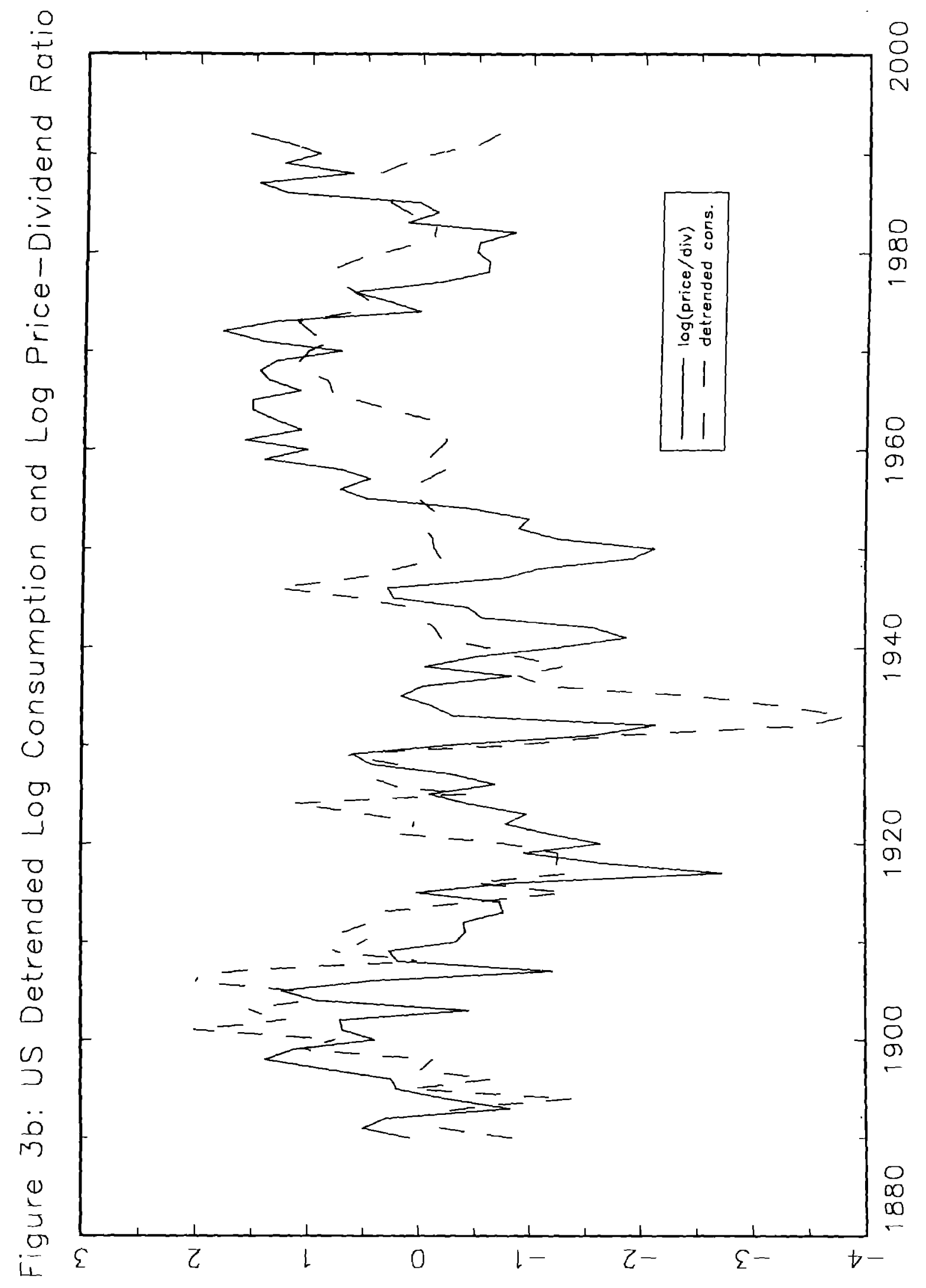

